\title{
Modeling of Oxidation Process of Coal Tar Pitch in Rotating Kilns
}

\author{
Jun Xie, ${ }^{1}$ Wenqi Zhong ${ }^{(D},{ }^{1}$ Yingjuan Shao ${ }^{D},{ }^{1}$ and Kaixi $\mathrm{Li}^{2}$ \\ ${ }^{1}$ Key Laboratory of Energy Thermal Conversion and Control of Ministry of Education, School of Energy and Environment, \\ Southeast University, Nanjing 210096, China \\ ${ }^{2}$ Institute of Coal Chemistry, Chinese Academy of Sciences, China
}

Correspondence should be addressed to Wenqi Zhong; wqzhong@seu.edu.cn

Received 17 May 2019; Accepted 23 June 2019; Published 7 July 2019

Guest Editor: Xizhong An

Copyright (C) 2019 Jun Xie et al. This is an open access article distributed under the Creative Commons Attribution License, which permits unrestricted use, distribution, and reproduction in any medium, provided the original work is properly cited.

\begin{abstract}
In this paper, a three-dimensional numerical model has been developed to study the process of oxidative weight increment of coal tar pitch in a rotating kiln. Based on the two-fluid method, the gas phase is modeled by realizable $k-\varepsilon$ turbulent model and the solid phase is modeled by kinetic theory of granular flow. The dense gas-solid flow, heat transfer, and oxidation reaction for the bed and freeboard regions are simultaneously solved. The model is applied to a rotating kiln with a cylinder of $0.75 \mathrm{~m}$ length and $0.4 \mathrm{~m}$ diameter in the front and circular truncated cone on exit side. The detailed verification of model is firstly performed by comparisons with the available experimental data. The particle velocity profiles, product gas compositions, and various forms of solid motion in rotary kilns are contrastively analyzed. Afterwards, simulations are carried out to obtain the primary hydrodynamic and reactive characteristics in the rotary kiln. At the steady state, the particle velocity peak is located at the active layer surface, while the velocity has the opposite direction in the passive layer. The bed region generally has a higher temperature than the freeboard due to the large thermal capacity. The concentrations of product gas compositions, such as $\mathrm{CO}_{2}, \mathrm{CO}$, and $\mathrm{CH}_{4}$, and solid product of oxidation, increase sharply near the surface and then keep on the steady values inside the bed. The effects of rotational speed of the rotary kiln and flow rate of air are also studied. The increasing rotational speed significantly accelerates the particle movement of the active layer and raises the final oxidative yield of coal pitch spheres. By contrast, increasing the flow rate of air has little effect on the particle motion and oxidation yield of coal pitch.
\end{abstract}

\section{Introduction}

The spherical activated carbon has the unique morphology, high wear resistance, and good hydrodynamic characteristics, which plays an important role in some special applications, such as air purification, blood purification, catalyst supports, chemical protective clothing, and others $[1,2]$. Traditional raw materials of activated carbon are mostly raw coal, but the reducing quantity of high-rank coal needs to expand the new production materials.

As a residue left by the distillation, a lot of coal tar pitch is produced during coal tar processing. The main components include polycyclic aromatic hydrocarbons and their derivatives. In recent years, coal tar pitch attracts more attention as a new raw material of the production of spherical activated carbon, due to its advantages of high carbon, low ash, and good plasticity [3].
The preparation of coal pitch-based spherical activated carbon consists of four processes: pitch modulation, pelletizing, oxidation stabilization, and carbonization-activation. Oxidation stabilization is the core among the four processes, which can be further categorized into four stages, namely, light component pyrolysis, preliminary oxidation, oxidative weight increment, and constant temperature oxidative weightlessness, respectively [4]. Through dozens of hours of low-temperature oxidation, the unstable components in coal pitch are decomposed into small molecular gases or condensed into stable macromolecules. The softening point is thereby improved to ensure that the sphere of coal tar pitch will not melt and deform during the subsequent carbonization-activation process [5]. The oxidation stabilization process consumes a lot of time and energy and dramatically impacts the capability of products; thus it is critical to choose the appropriate manufacturing technology. 
Rotary kilns are widely applied in modern industry, such as cement, metallurgy, chemicals, and energy field due to their good mixing performance, high heat transfer efficiency, and large handling capacity $[6,7]$. In addition, the relatively low particle motion velocity in rotary kilns results in the small collision force between particles and between particle and wall. Considering the friability of pitch spheres and the demand of high heat capacity in the oxidation process, the features of rotary kilns are very applicable for the oxidation stabilization of coal tar pitch spheres. In the past decades, modeling and numerical simulation have been used to provide a detailed insight and quantitative guidelines for reactor design and optimization. However, existing work for rotary kilns focuses on the flow field [7-9], mixing/segregation [10$13]$, and heat transfer performance $[6,14,15]$; simulation of chemical processes in a rotary kiln is still in its infancy due to the complexity of coupling of dense gas-solid flow, heat transfer, and reactions [16]. There are only few modeling researches concerning the reacting flow for rotary kilns, which can be categorized two types. The first one is modeling the motion and chemistry under steady condition, and the other one is separately modeling the processes for bed region and freeboard region, respectively. Montagnaro et al. [17] presented a 1.5-dimensional (1.5D) model for oxy-pyrolysis of sewage sludge at the steady state in a rotary kiln. Babler et al. [18] developed a modular numerical model for biomass pyrolysis in a rotary kiln, which considered the solid bed region and gas phase domain at steady state. Mujumdar and Ranade [16] developed separate but coupled computational models for bed and freeboard regions for rotary cement kiln. The reactions in the bed region were modeled through single-phase pseudo fluid, and combustion of coal particles in the freeboard region was modeled by Eulerian-Lagrangian approach. Du et al. [19] studied the combustion of pulverized coal in the airflow of cement rotary kiln using EulerianLagrangian method, which belonged to the dilute particle flow. During the chemistry of rotary kilns, the reaction process is dynamic and complicated due to the dense particles motion, gas turbulence, and multicoupling between the gas and solid phases. Therefore, the simultaneous modeling of dense gas-solid flow, heat transfer, and chemical reactions for the whole rotary kilns is of the pressing need at present, but relevant researches have not been found in the available literature. In addition, the characteristics derived from the $2 \mathrm{D}$ or quasi-3D cross section might not be applicable to the $3 \mathrm{D}$ system due to the wall and geometry impacts on the flow field and reactive characteristics. The real 3D modeling is critical to acquire the complete information inside the rotary kiln.

The present work develops a comprehensive 3D model to study the key oxidation process, oxidative weight increment, in a rotating kiln. Based on the two-fluid method, the model simultaneously solves the dense gas-solid motion, heat transfer, and chemical reaction for the entire regions of a rotary kiln. The rotary kiln has a cylinder of $0.75 \mathrm{~m}$ length and $0.4 \mathrm{~m}$ diameter in the front and circular truncated cones on exit side. The detailed verification of model is firstly performed by comparisons with the available experimental data. Afterwards, the solid flow field, profiles of velocity and temperature, the concentrations of gas compositions
$\left(\mathrm{O}_{2}, \mathrm{CO}_{2}, \mathrm{CO}\right.$, and $\left.\mathrm{CH}_{4}\right)$, and the oxidized coal pitch inside the rotary kiln are analyzed. Finally, the effects of air flow rate and rotating speed of the rotary kiln on the primary particle movement and reactive characteristics are emphatically studied.

\section{Model Descriptions}

Based on the Eulerian-Eulerian (two-fluid) method and kinetic theory of granular flow, the conservation equations of continuity, momentum, energy, and species are solved for gas and solid phases, respectively. In consideration of the particularity of gas-solid motion in rotary kilns, the gas phase is modeled by realizable $k-\varepsilon$ turbulent model, and Johnson and Jackson model is used for the frictional stress. The governing equations are briefly presented in the following sections, the details of which can be found in literatures $[20,21]$.

2.1. Governing Equations. The mass equations of gas and solid phases are written as [21]

$$
\begin{gathered}
\frac{\partial\left(\alpha_{g} \rho_{g}\right)}{\partial t}+\nabla \cdot\left(\alpha_{g} \rho_{g} v_{g}\right)=S_{g s} \\
\frac{\partial\left(\alpha_{s} \rho_{s}\right)}{\partial t}+\nabla \cdot\left(\alpha_{s} \rho_{s} v_{s}\right)=S_{s g}
\end{gathered}
$$

where $\alpha, \rho$, and $v$ are the volume fraction, density, and velocity vector, respectively. The mass source term $S$ from heterogeneous reactions is expressed as

$$
S_{g s}=M_{c} \sum \gamma_{c} r=-S_{s g}
$$

where $M, \gamma$, and $r$ represent molecular weight, stoichiometric coefficient, and chemical reaction rate, respectively.

The species transport equations for two phases are [21]

$$
\frac{\partial\left(\alpha \rho Y_{i}\right)}{\partial t}+\nabla \cdot\left(\alpha \rho Y_{i} v\right)=\nabla \cdot \alpha J_{i}+R_{i}
$$

where $Y_{i}$ and $R_{i}$ are mass fraction and the net rate of species $i$. The diffusion flux $J_{i}$ takes the form

$$
J_{i}=-\left(\rho D_{i}+\frac{\mu_{t}}{S c_{t}}\right) \nabla Y_{i}
$$

where $S c_{t}$ is the Schmidt number and $D$ is the coefficient of turbulent mass diffusion. [21]

The momentum equation for gas phase is expressed as

$$
\begin{aligned}
& \frac{\partial\left(\alpha_{g} \rho_{g} v_{g}\right)}{\partial t}+\nabla \cdot\left(\alpha_{g} \rho_{g} v_{g} v_{g}\right) \\
& =-\alpha_{g} \nabla p_{g}+\alpha_{g} \rho_{g} g-\beta\left(v_{g}-v_{s}\right)+\nabla \cdot\left(\alpha_{g} \tau_{g}\right) \\
& \quad+S_{g s} u_{s}
\end{aligned}
$$

where $p, \tau_{g}$, and $u_{s}$ represent the gas pressure, gas stress tensor, and the particle mean velocity, respectively. The term 
$S_{\text {gs }} u_{\mathrm{s}}$ indicates the momentum exchange between the gas and solid phases.

The gas-solid interphase drag coefficient $\beta$ is derived from Gidaspow model [22]:

$$
\begin{aligned}
\beta & = \begin{cases}\frac{3}{4} \frac{\alpha_{s} \alpha_{g} \rho_{g}\left|\boldsymbol{v}_{g}-\boldsymbol{v}_{s}\right|}{d_{s}} C_{D} \alpha_{g}{ }^{-2.65} & \alpha_{g}>0.8 \\
150 \frac{\alpha_{s}^{2} \mu_{g}}{\alpha_{g} d_{s}^{2}}+1.75 \frac{\rho_{g} \alpha_{s}\left|\boldsymbol{v}_{g}-\boldsymbol{v}_{s}\right|}{d_{s}} & \alpha_{g} \leq 0.8\end{cases} \\
C_{D} & = \begin{cases}0.44 & \operatorname{Re}_{s}>1000 \\
\frac{24}{\operatorname{Re}}\left[1+0.15 e_{s}{ }^{0.687}\right] & \operatorname{Re}_{s} \leq 1000\end{cases} \\
R e_{s} & =\frac{\alpha_{g} \rho_{g}\left|\boldsymbol{v}_{g}-v_{s}\right| d_{s}}{\mu_{s}}
\end{aligned}
$$
[20]

The viscous stress tensor for the gas phase is expressed as

$$
\begin{aligned}
& \tau_{g}=\mu_{g}\left(\nabla v_{g}+\nabla v_{g}^{T}\right)-\frac{2}{3} \mu_{g}\left(\nabla \cdot v_{g}\right) I \\
& \mu_{g}=\mu_{g l}+\mu_{g t}
\end{aligned}
$$

where the $\mu_{\mathrm{g}}$ is gas shear viscosity, and $\mu_{\mathrm{gl}}$ is the laminar viscosity. The turbulent viscosity $\mu_{\mathrm{gt}}$ can be provided by turbulence kinetic energy $k$ and dissipation rate $\varepsilon$ :

$$
\mu_{g t}=\rho_{g} C_{\mu} \frac{k^{2}}{\varepsilon}
$$

where $C_{\mu}$ is the model constant.

The realizable $k-\varepsilon$ turbulence model has exhibited the significant improvements over the standard $k-\varepsilon$ model, where the flow features consist of strong streamline curvature, vortices, and rotation. Therefore, the realizable $k-\varepsilon$ model is used to simulate the turbulent motion of gas and solid in the rotary kiln.

Considering the complication of expressions of realizable $k-\varepsilon$ model for each phase, only the fundamental transport equations are given here. Detailed expressions can be found in literature [23].

$$
\begin{aligned}
& \frac{\partial}{\partial t}(\rho k)+\nabla \cdot\left(\rho v_{g} k\right) \\
& =\nabla \cdot\left(\frac{\mu_{t}}{\sigma_{k}} \nabla \cdot k\right)+G_{k}+G_{b}-\rho \varepsilon \\
& \frac{\partial}{\partial t}(\rho \varepsilon)+\nabla \cdot(\rho v \varepsilon) \\
& =\nabla \cdot\left(\frac{\mu_{t}}{\sigma_{k}} \nabla \cdot \varepsilon\right)+\rho C_{\varepsilon 1} E \varepsilon-\rho C_{\varepsilon 2} \frac{\varepsilon^{2}}{k+\sqrt{v \varepsilon}} \\
& \quad+C_{1 \varepsilon} \frac{\varepsilon}{k} C_{3 \varepsilon} G_{b}
\end{aligned}
$$

where $G_{k}$ is the generation of turbulence kinetic energy and $G_{b}$ is the generation of turbulence kinetic energy due to buoyancy. $C_{\varepsilon 2}, C_{1 \varepsilon}$, and $C_{3 \varepsilon}$ are the constants, and the $\sigma_{k}$ and $\sigma_{\varepsilon}$ are the turbulent Prandtl numbers. The relevant expressions are listed as follows [23]:

$$
\begin{aligned}
G_{k}= & \mu_{g t} \Delta v_{g} \\
& \cdot\left[\Delta v_{g}+\left(\Delta v_{g}\right)^{T}-\frac{2}{3} \Delta v_{g}\left(\mu_{g t} \Delta v_{g}+\rho_{g} k\right)\right] \\
G_{b}= & \kappa g_{i} \frac{\mu_{t}}{P r_{t}} \frac{\partial T}{\partial x_{i}} \\
C_{\varepsilon 1}= & \max \left[0.43+\frac{\eta}{\eta+5}\right] \\
\eta= & \left(2 E_{i j} E_{i j}\right)^{1 / 2} \frac{k}{\varepsilon} \\
E_{i j}= & \frac{1}{2}\left(\frac{\partial u_{i}}{\partial x_{j}}+\frac{\partial u_{j}}{\partial x_{i}}\right)
\end{aligned}
$$

The momentum equation for solid phase is written as [21]

$$
\begin{aligned}
& \frac{\partial\left(\alpha_{s} \rho_{s} v_{s}\right)}{\partial t}+\nabla \cdot\left(\alpha_{s} \rho_{s} v_{s} v_{s}\right) \\
& \quad=-\alpha_{s} \nabla p+\alpha_{s} \rho_{s} g-\beta\left(v_{s}-v_{s}\right)+\nabla \cdot\left(\alpha_{s} \tau_{s}\right)+S_{s g} u_{s}
\end{aligned}
$$

where $\tau_{s}$ is the solid phase stress tensor and takes Newtonian form [21]

$$
\begin{aligned}
\tau_{s}= & {\left[\left(-p_{s}+\lambda_{s} \nabla \cdot v_{s}\right)+\mu_{s}\left[\nabla v_{s}+\left(\nabla v_{s}\right)^{T}\right]\right.} \\
& \left.-\frac{2}{3}\left(\nabla \cdot v_{s}\right)\right] I \\
\lambda_{s} & =\frac{4}{3} \alpha_{s} \rho_{s} d_{s} g_{0}(1+e) \sqrt{\frac{\Theta_{s}}{\pi}} \\
\mu_{s} & =\frac{4}{5} \alpha_{s}^{2} \rho_{s} d_{s} g_{0}(1+e) \sqrt{\frac{\Theta_{s}}{\pi}}+\frac{10 \rho_{s} d_{s} \sqrt{\pi \Theta_{s}}}{96(1+e) \alpha_{s} g_{0}}[1 \\
& \left.+\frac{4}{5} \alpha_{s} g_{0}(1+e)\right]^{2}+\frac{p_{s} \sin \phi}{2 \sqrt{I_{2 D}}}
\end{aligned}
$$

The granular temperature of solid phase, $\Theta$, can be derived from the following equations [21]:

$$
\begin{aligned}
& \frac{3}{2}\left[\frac{\partial}{\partial t}\left(\alpha_{s} \rho_{s} \Theta_{s}\right)+\nabla \cdot\left(\alpha_{s} \rho_{s} \Theta_{s} u_{s}\right)\right] \\
& =-\left(p_{s} I+\tau_{s}\right): \nabla u_{s}+\nabla \cdot\left(k_{s} \nabla \Theta_{s}\right)-\gamma-3 \beta \Theta_{s} \\
& k_{s} \\
& =\frac{150 \rho_{s} d_{s} \sqrt{\Theta_{s} \pi}}{384(1-e) g_{0}}\left[1+\frac{6}{5} \alpha_{s} g_{0}(1+e)\right]^{2} \\
& \quad+2 \rho_{s} \alpha_{s}^{2} d_{s} g_{0}(1+e) \sqrt{\frac{\Theta_{s}}{\pi}}
\end{aligned}
$$




$$
\begin{aligned}
& \gamma=3\left(1-e^{2}\right) \alpha_{s}^{2} \rho_{s} \Theta_{s}\left(\frac{4}{d_{s}} \sqrt{\frac{\Theta}{\pi}}-\nabla u_{s}\right) \\
& g_{0}=\left[1-\left(\frac{\alpha_{s}}{\alpha_{s, \max }}\right)^{1 / 3}\right]^{-1}
\end{aligned}
$$

The solid pressure $p_{s}$ is written as [23]

$$
p_{s}=p_{\text {kinetic }}+p_{\text {friction }}
$$

The kinetic pressure $p_{\text {kinetic }}$ indicates the normal force of collision between particles, and the Lun model is used [20].

$$
p_{\text {kinetic }}=\alpha_{s} \rho_{s} \Theta\left[1+2 g_{0} \alpha_{s}(1+e)\right]
$$

In the bed region of the rotary kiln, solid volume fraction is very high and instantaneous particles collision is less important. The frictional stress needs to be taken into account when the solid concentration exceeds a critical value. The frictional pressure model proposed by Johnson and Jackson [24] is used in this simulation:

$$
p_{\text {friction }}=\operatorname{Fr} \frac{\left(\alpha_{s}-\alpha_{s, \text { min }}\right)^{n}}{\left(\alpha_{s, \max }-\alpha_{s}\right)^{P}}
$$

where the coefficients $n=2$ and $p=5$ [25]. The value of $\alpha_{s, \min }$ is normally set to 0.5 for the 3D flow and the maximum packing limit $\alpha_{s, \text { max }}$ is 0.63 . The coefficient $F r$ is a function of the critical solid concentration:

$$
F r=0.1 \alpha_{s}
$$

The frictional viscosity is expressed as

$$
\mu_{\text {friction }}=p_{\text {friction }} \sin \phi
$$

where $\phi$ is the angle of internal friction.

The enthalpy equations are used to describe the energy conservation for gas phase and solid phase. Heat conduction, heat convection, and heat exchange between two phases are taken into account [21].

$$
\begin{aligned}
& \frac{\partial}{\partial t}\left(\alpha_{g} \rho_{g} H_{g}\right)+\nabla \cdot\left(\alpha_{g} \rho_{g} v_{g} H_{g}\right) \\
& \quad=\nabla\left(\lambda_{g} \nabla T_{g}\right)+h_{g s}\left(T_{g}-T_{s}\right)+S_{g s} H_{s} \\
& \frac{\partial}{\partial t}\left(\alpha_{s} \rho_{s} H_{s}\right)+\nabla \cdot\left(\alpha_{s} \rho_{s} v_{s} H_{s}\right) \\
& \quad=\nabla\left(\lambda_{s} \nabla T_{s}\right)+h_{s g}\left(T_{s}-T_{g}\right)+S_{s g} H_{s}
\end{aligned}
$$

where $H, \lambda$, and $h$ represent the specific enthalpy, mixture thermal conductivity, and convective heat transfer coefficient, respectively. The $S_{s g} H_{s}$ is the heat exchange because of heterogeneous reactions.

The convective heat transfer coefficient between the two phases is given by

$$
h_{g s}=h_{s g}=\frac{6 \lambda_{g} \alpha_{g} \alpha_{s} N u_{s}}{d_{s}^{2}}
$$

The Nusselt number correlation is provided by Gunn [20]:

$$
\begin{aligned}
N u_{s}= & \left(7-10 \alpha_{g}+5 \alpha_{g}^{2}\right)\left(1+0.7 \operatorname{Re}_{s}^{0.2} \operatorname{Pr}^{1 / 3}\right) \\
& +\left(1.33-2.4 \alpha_{g}+1.2 \alpha_{g}^{2}\right) \operatorname{Re}_{s}^{0.7} \operatorname{Pr}^{1 / 3}
\end{aligned}
$$

where Pr is Prandtl number of each phase.

2.2. Chemical Reactions. The oxidation stabilization process of coal tar pitch sphere can be categorized into four stages, which are briefly described as follows. In the first stage, the temperature is mainly in the range of $20 \sim 140^{\circ} \mathrm{C}$. The light components of coal pitch are released and weight loss is about $5 \sim 15 \%$ at this stage. The coal pitch sphere reaches the maximum weight loss rate at the midpoint of the segment. The second stage is from 140 to $200^{\circ} \mathrm{C}$, where preliminary oxidation of the pitch happens and the mass reduction rate slows down with weight loss about $3 \%$. In this stage, with the increase of temperature, the oxidation reaction rate increases. Although there exists volatiles release, the loss of weight is small and the loss rate is slow. The third stage is located in the range of $200 \sim 300^{\circ} \mathrm{C}$. The significant oxidative weight increment of coal pitch takes place, gaining weight about 3\%. At this stage, the pyrolysis is basically completed, and the oxidation rate significantly increases due to the higher temperature. The combination of oxygen makes up for the quality loss caused by the dehydrogenation of the side chain of pitch molecule. The coal tar pitch reaches the maximum weight gain rate at the midpoint of the segment. Thereafter, with the increase of temperature, the growth rate gradually decreases. Stage four is the period of constant temperature oxidative weightlessness at about $300^{\circ} \mathrm{C}$. The oxidative reaction rate is basically stable, and the cross-linked polymerization of aromatics alkylation and dehydrogenation of the medium-temperature pitch take place at this stage.

As the most key oxidation process, oxidative weight increment of coal tar pitch at the temperature range of 200 $300^{\circ} \mathrm{C}$ is modeled in this paper. The primary assumptions introduced for the simplification of calculation process are listed as follows:

(1) the gaseous products of oxidation process are $\mathrm{CO}_{2}$, $\mathrm{CO}, \mathrm{CH}_{4}, \mathrm{H}_{2} \mathrm{O}$, and tar; the other small molecule hydrocarbons generally present in insignificant amounts and hence are neglected;

(2) the equivalent formulae of the coal pitch and oxidized coal pitch are derived from the ultimate analysis of the relevant species, as shown in Table 1;

(3) the radiative heat transfer is not taken into account because the attribution of radiation in a rotary kiln is less than $3 \%$ at the temperature of $300^{\circ} \mathrm{C}$ [26].

Based on the above assumption, the solid phase consists of two species: coal pitch (before oxidation) $\mathrm{C}_{7.62} \mathrm{H}_{3.44} \mathrm{O}_{0.243}$, and oxidized coal pitch (after oxidation) $\mathrm{C}_{7.19} \mathrm{H}_{3.1} \mathrm{O}_{0.581}$; the gas phase involves seven components: oxygen $\mathrm{O}_{2}$, nitrogen $\mathrm{N}_{2}$, carbon dioxide $\mathrm{CO}_{2}$, water vapor $\mathrm{H}_{2} \mathrm{O}$, carbon monoxide $\mathrm{CO}$, methane $\mathrm{CH}_{4}$, and tar. Because of minor amount of formation, the nitrogen oxide and sulfur oxide are not taken into account. 
TABLE 1: Ultimate analyses of coal tar pitch spheres before and after oxidative stabilization.

\begin{tabular}{lcccrr}
\hline Stage & $\mathrm{C}$ & $\mathrm{H}$ & $\mathrm{O}$ & $\mathrm{N}$ \\
\hline Initial state & 91.437 & 3.526 & 3.722 & 0.876 & 0.439 \\
Before oxidation & 91.383 & 3.436 & 3.895 & 0.845 & 0.440 \\
After oxidation & 86.271 & 3.098 & 9.303 & 0.966 & 0.361 \\
\hline
\end{tabular}

TABLE 2: The typical measured data of the experiments.

\begin{tabular}{|c|c|c|c|c|c|c|c|c|c|}
\hline $\begin{array}{l}200 \\
I^{\circ} \mathrm{C} \\
\end{array}$ & $\begin{array}{c}\text { Time } \\
\text { /s }\end{array}$ & $\begin{array}{c}\mathrm{CO}_{2} \\
1 \% \\
\end{array}$ & $\begin{array}{c}\mathrm{CO} \\
/ \mathrm{ppm}\end{array}$ & $\begin{array}{c}\mathrm{CH}_{4} \\
/ \% \\
\end{array}$ & $\begin{array}{l}300 \\
{ }^{\circ} \mathrm{C} \\
\end{array}$ & $\begin{array}{c}\text { Time } \\
\text { /s }\end{array}$ & $\begin{array}{c}\mathrm{CO}_{2} \\
1 \% \\
\end{array}$ & $\begin{array}{c}\mathrm{CO} \\
/ \mathrm{ppm}\end{array}$ & $\begin{array}{c}\mathrm{CH}_{4} \\
1 \% \\
\end{array}$ \\
\hline Test 1 & $0: 00: 57$ & 0 & 73 & 0 & Test 1 & $0: 00: 12$ & 0.9 & 1971 & 0.1 \\
\hline Test 2 & 0:01:28 & 0 & 86 & 0 & Test 2 & 0:00:42 & 1 & 2261 & 0.1 \\
\hline Test 3 & 0:01:58 & 0 & 74 & 0 & Test 3 & 0:01:12 & 1.2 & 2636 & 0.2 \\
\hline Test 4 & $0: 02: 29$ & 0 & 72 & 0 & Test 4 & 0:01:43 & 1 & 2468 & 0.2 \\
\hline Test 5 & 0:02:59 & 0 & 76 & 0 & Test 5 & 0:02:13 & 1 & 2211 & 0.1 \\
\hline Test 6 & 0:03:29 & 0 & 68 & 0 & Test 6 & 0:02:43 & 1 & 2211 & 0.1 \\
\hline Test 7 & 0:04:00 & 0 & 76 & 0 & Test 7 & 0:03:14 & 0.9 & 2197 & 0.1 \\
\hline Test 8 & 0:04:30 & 0 & 90 & 0 & Test 8 & $0: 03: 44$ & 1 & 2347 & 0.1 \\
\hline Test 9 & 0:05:00 & 0 & 68 & 0 & Test 9 & 0:04:14 & 1.1 & 2609 & 0.2 \\
\hline
\end{tabular}

During the process of oxidative weight increment, the coal pitch sphere is oxidized and volatile components are released into the rotary kiln. The composition balance of the oxidation reaction is considered as follows:

$$
\begin{aligned}
& \text { Coal pitch }+n_{1} \mathrm{O}_{2} \longrightarrow \\
& m_{1} \text { Oxidized coal pitch }+n_{2} \mathrm{CO}_{2}+n_{3} \mathrm{CO}+n_{4} \mathrm{CH}_{4} \\
& \quad+n_{5} \mathrm{H}_{2} \mathrm{O}+n_{6} \mathrm{Tar}
\end{aligned}
$$

In (R1), the stoichiometric coefficient of oxidized coal pitch, $m_{1}$, is determined based on the previous experimental data of oxidation stabilization [4] and ultimate analysis shown in Table 1. The coefficient of tar is derived from another thermogravimetric experiment [27]. The TG and DTG curves of the pitch fractions under $\mathrm{N}_{2}$ and air atmosphere showed that the weight loss of tar between $200 \sim 300^{\circ} \mathrm{C}$ is about $3 \%$. The coefficients of gas compositions, $n_{1} \sim n_{5}$, are obtained by the current experimental results in Table 2 and the mass balance calculation.

Guo et al. [4] experimentally studied the oxidation stabilization process of coal pitch spheres. The kinetic parameters, such as activation energy and preexponential factor, and reaction mechanism function, $f(\chi)$, under four reaction stages were deduced, which were of different values and expressions. Based on the results, the equation of reaction rate and the relevant mechanism expression of oxidative weight increment are given as follows:

$$
\begin{aligned}
r & =A \exp \left(\frac{-E}{R T_{s}}\right) f(\chi) \\
f(\chi) & =\frac{1}{3}(1-\chi)[-\ln (1-\chi)]^{-2} \\
\chi & =\frac{m_{0}-m_{t}}{m_{0}-m_{\infty}}
\end{aligned}
$$

where $m_{0}, m_{t}$, and $m_{\infty}$ are the initial, instantaneous, and ultimate amounts of coal pitch sphere, respectively. The reaction kinetics parameters in this simulation are derived from experimental data [4]: $\ln \mathrm{A}=120.24$ and $\mathrm{E}=533.84 \mathrm{~kJ} /$ mol.

2.3. Experiment System and Computational Conditions. The experimental setup and simulation schematic diagram of the rotary kiln are shown in Figure 1. The experiments were conducted for the oxidation stabilization of coal tar pitch sphere at Institute of Coal Chemistry, Chinese Academy of Sciences. The rotating kiln has a cylinder of $0.75 \mathrm{~m}$ length and $0.4 \mathrm{~m}$ inner diameter in the front and circular truncated cone of $0.2 \mathrm{~m}$ top diameter on right side, which is made of heatresistant steel and insulated with insulation material inside the enclosure. The rotary kiln is heated by the electric heaters, and the temperature rise is regulated through the subsection control program: at room temperature to $140^{\circ} \mathrm{C}$, the setting time is $1 \mathrm{~h} ; 140 \sim 200^{\circ} \mathrm{C}$, the setting time is $5 \mathrm{~h} ; 200 \sim 300^{\circ} \mathrm{C}$, time is set to $10 \mathrm{~h}$; constant temperature at $300^{\circ} \mathrm{C}$, the time lasts $1 \mathrm{~h}$. The air is continuously introduced to the rotary kiln from four small pipes at the left side. As a batch reactor, this rotary kiln is horizontal and the particles of oxidized coal tar pitch are extracted at the end of the reaction. At the monitoring temperature range of $200 \sim 300^{\circ} \mathrm{C}$, the flue gas compositions at the exit of rotary kiln, such as $\mathrm{O}_{2}, \mathrm{CO}_{2}$, $\mathrm{CO}$, and $\mathrm{CH}_{4}$, are measured by gas analysis instrument in real-time monitoring. For the sake of simplicity, the typical measured data at 200 and $300^{\circ} \mathrm{C}$ are given in Table 2 . The measurements are repeated nine times for averaging at each temperature point. The oxidized coal pitch spheres are sampled for elemental analysis at intervals of $10^{\circ} \mathrm{C}$ and the elemental composition before and after oxidative stabilization is presented in Table 1. The results obtained from the experiments will be used for the kinetic data and comparative basis. 


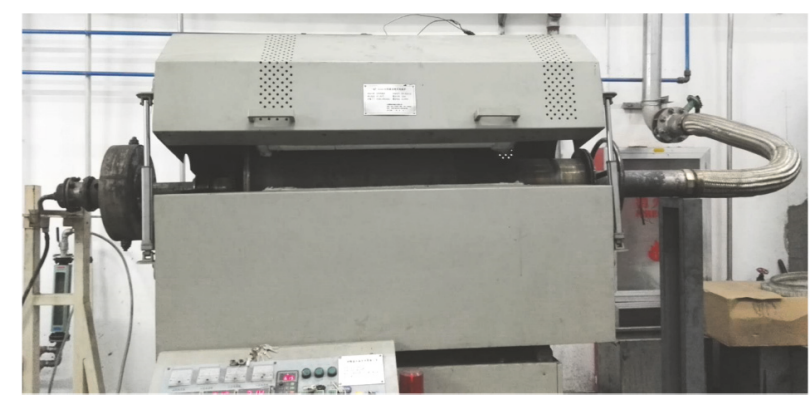

(a)

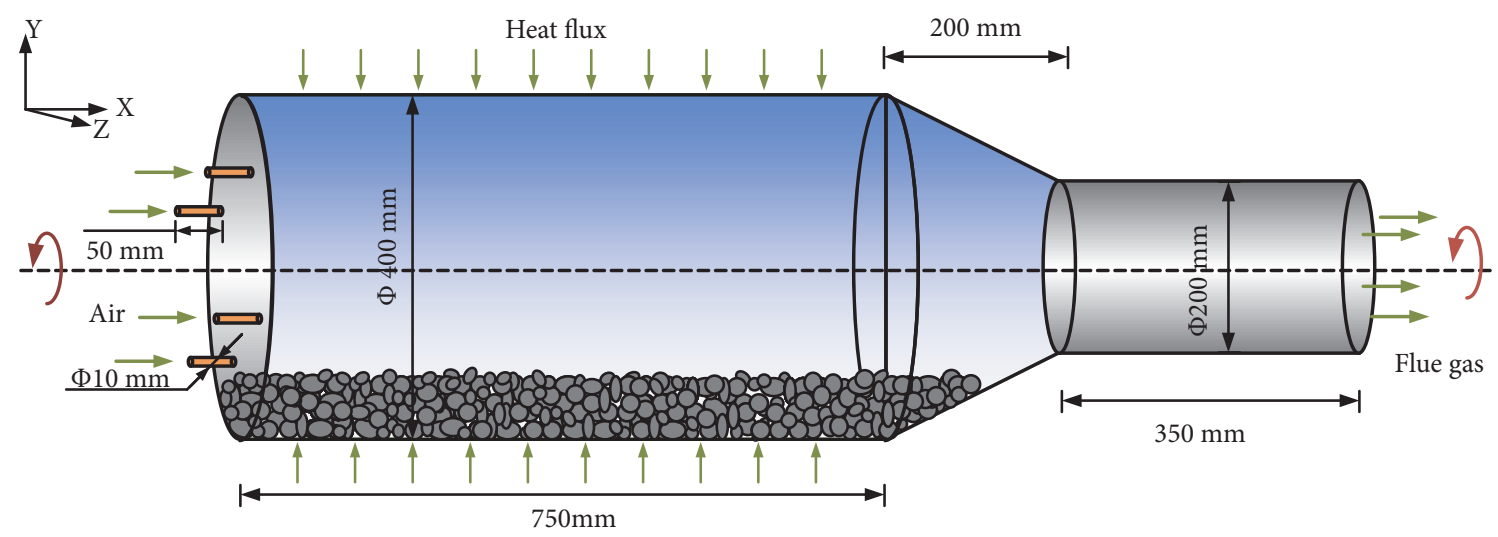

(b)

Figure 1: The setup and schematic diagrams of rotary kiln: (a) setup diagram; (b) schematic diagram.

In this paper, the 3D Eulerian-Eulerian model is applied to simulate the oxidation process in a rotating kiln. The base case is built in accordance with the setting of experiments. Initially, the particles of coal tar pitch are located at the bottom of the kiln with solid volume fraction of 0.55 , and the packing limit is set as 0.6. The air is introduced into the kiln through four gas inlets at a specified velocity. At the right outlet, the boundary condition of pressure-outlet with atmosphere is adopted. At the walls, the no-slip and moving/rotational condition is set, and the fixed heat flux is specified. The second-order upwind discretization scheme is used for momentum term, while other convective terms adopt first-order upwind. The constant time step of $1 \times 10^{-4} \mathrm{~s}$ is set for the calculation. Detailed modeling conditions and parameter settings are given in Table 3. The simulation was conducted based on 8 processes parallel on an Intel w5580 workstation.

The sliding mesh model is used to simulate the rotating movement of kilns. The cylindrical section is divided by hexahedral mesh, and the circular truncated cone is divided by tetrahedral mesh. Four different grid domains are tested to perform the validation of the mesh independence, which contain 222 342, 398 468, 618 327, and 788361 grid cells, respectively. The profiles of the particle velocities along the bed depth and bed surface at $x=0.375 \mathrm{~m}$ are shown in Figure 2 . With the increase of grid number, the velocity profiles generally reduce first and then increase, but the variation of simulation results is much little when the grid cells increase to 618327 . Therefore, in terms of the computation time and
TABLE 3: Summary of relevant parameters of simulations.

\begin{tabular}{lc}
\hline Description & Parameters \\
\hline Particle diameter, $d_{s}(\mathrm{~mm})$ & 1.0 \\
Particle density, $\rho_{s}\left(\mathrm{~kg} / \mathrm{m}^{3}\right)$ & 1435 \\
Particle viscosity, $\mu_{s}(\mathrm{~Pa} \cdot \mathrm{s})$ & 0.18 \\
Particle thermal conductivity, $\lambda_{s}$ & 2000 \\
$(\mathrm{~W} / \mathrm{m} \cdot \mathrm{K})$ & 8 \\
Inventory of particles, $G_{b}(\mathrm{~kg})$ & $10,25,37.5,50$, \\
Air flow rate, $V_{a}\left(\mathrm{Nm}^{3} / \mathrm{h}\right)$ & 62.5 \\
Air temperature, $T_{a}\left({ }^{\circ} \mathrm{C}\right)$ & 25 \\
Rotational speed of kiln, $\omega(\mathrm{rpm})$ & $0.33,0.95,1.43$, \\
Heat flux, $h_{w}\left(\mathrm{~W} / \mathrm{m}^{2}\right)$ & $1.91,2.39$ \\
Temperature of rotary kiln, $T_{b}\left({ }^{\circ} \mathrm{C}\right)$ & 150 \\
\hline
\end{tabular}

calculation accuracy, the computational domain containing 618327 mesh cells is selected for the following work.

\section{Results and Discussions}

3.1. Model Validation. With the purpose of verification of the established 3D model, the hydrodynamic and reactive characteristics in rotary kilns are compared with experimental data. Considering the lack of data of particle motion in our experiments, the results from the Boateng et al. [28] 


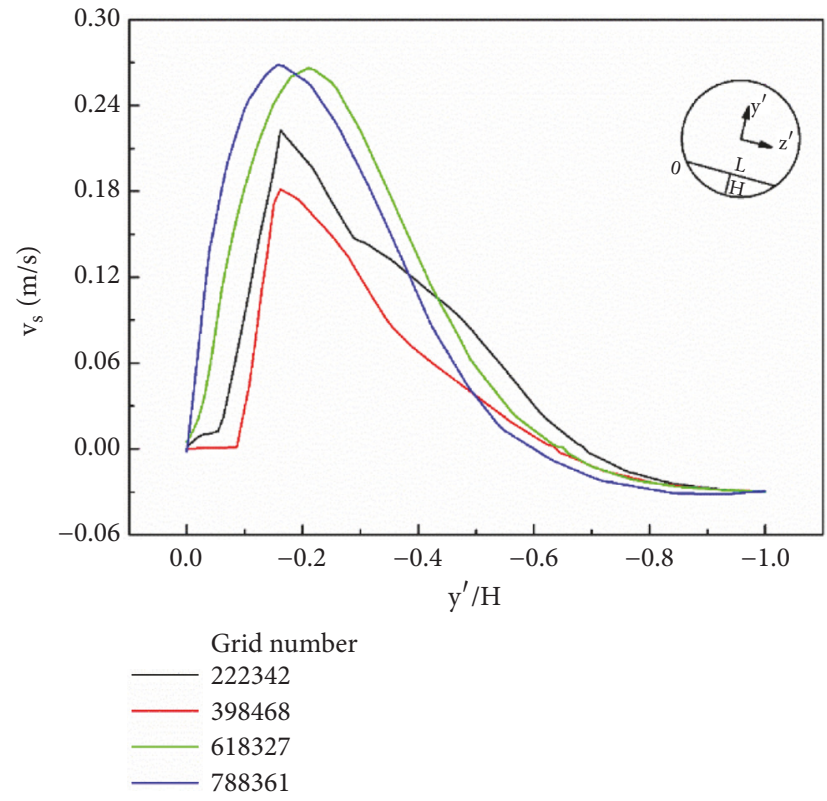

(a)

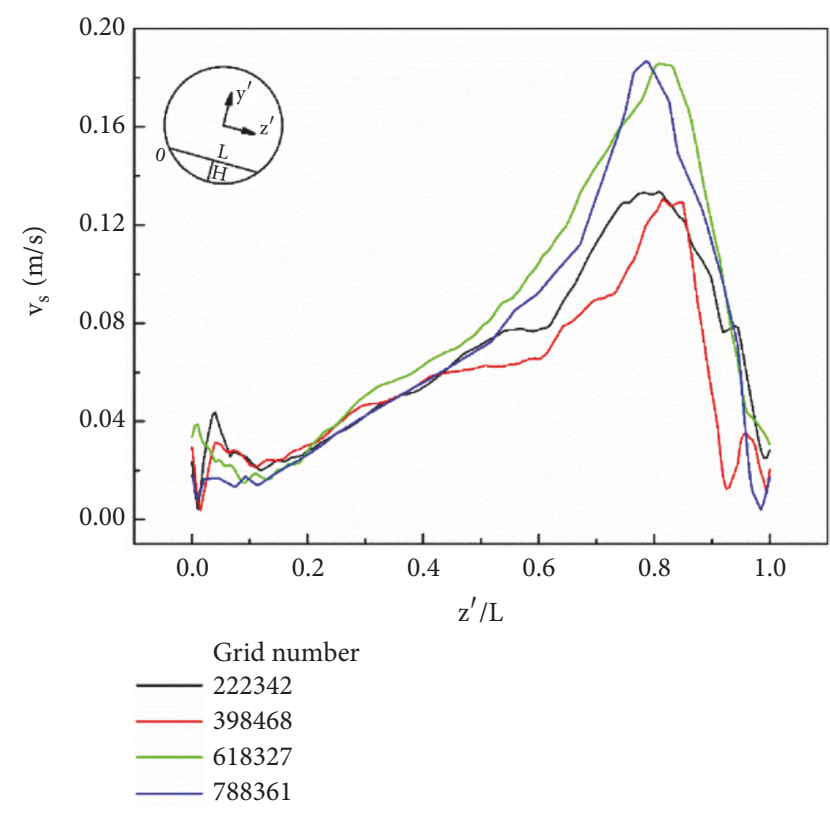

(b)

FIGURE 2: Variations of particle velocity profiles with grid number: (a) depth velocity; (b) surface velocity.

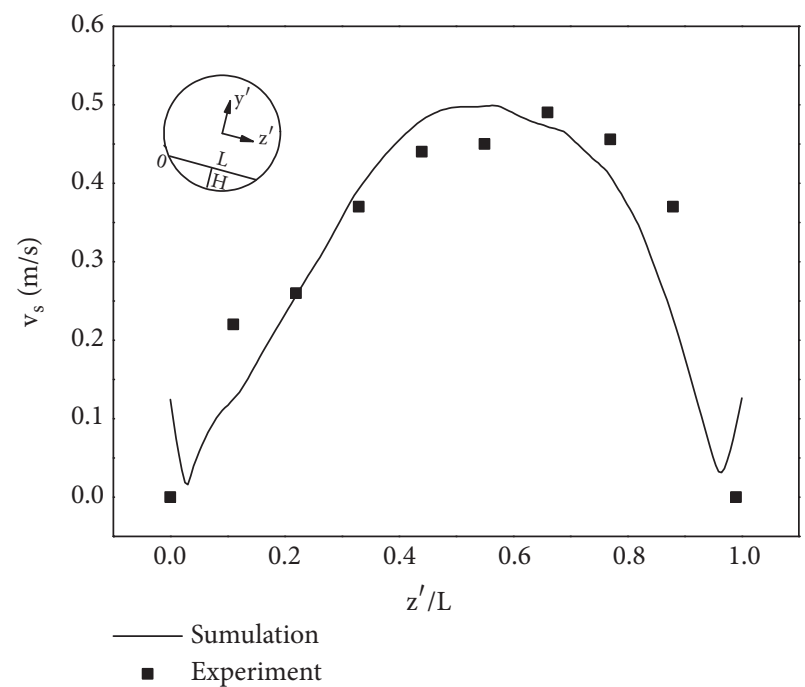

(a)

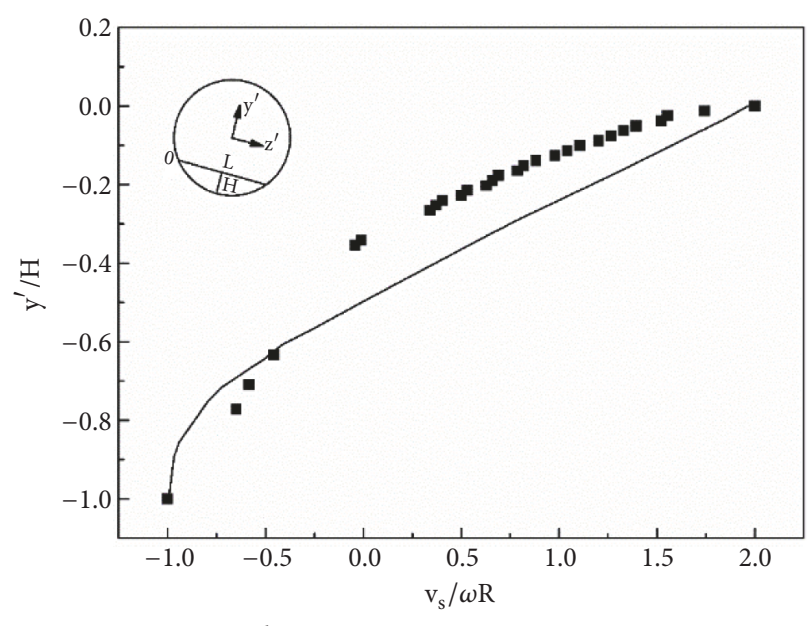

- Experiment

(b)

FIGURE 3: Particle velocity profiles along the bed surface and depth: (a) surface direction; (b) depth direction.

are used to validate the present model. The selected particle material is the polyethylene pellet with uniformly spherical shape. The rotary drum comprises a $964 \mathrm{~mm}$ inside diameter and $1000 \mathrm{~mm}$ axial length. According to the experimental data, the flow field at an axial distance of $220 \mathrm{~mm}$ from the end-piece belongs to the undisturbed region. For the sake of simplification, the simulated rotary kiln length is reduced to $500 \mathrm{~mm}$. The polyethylene pellets with $3.63 \mathrm{~mm}$ size and $960 \mathrm{~kg} / \mathrm{m}^{3}$ density are loaded at 3.3\% fill and operated at the rotational rates of 3 and $5 \mathrm{rpm}$. Detailed particle properties and operating parameters can be found in literature [28]. Representative results including particle velocities along the bed surface and depth in the midsection are shown in Figure 3. The surface velocity presents a parabolic profile skewing towards the bottom. The depth velocity at the midchord position presents the maximum value at the bed surface, and the velocity conforms to the tangential velocity at the wall position. Generally, the predicted results along the bed surface and depth compare well with experimental data.

Subsequently, a base case of the oxidation stabilization of coal tar pitch is applied to evaluate the predictive ability of two-fluid model coupled with chemical reaction. As listed in Table 3, the experiments of the base case are operated at the air flow rate with $10 \mathrm{Nm}^{3} / \mathrm{h}$ and rotational speed with 0.33 


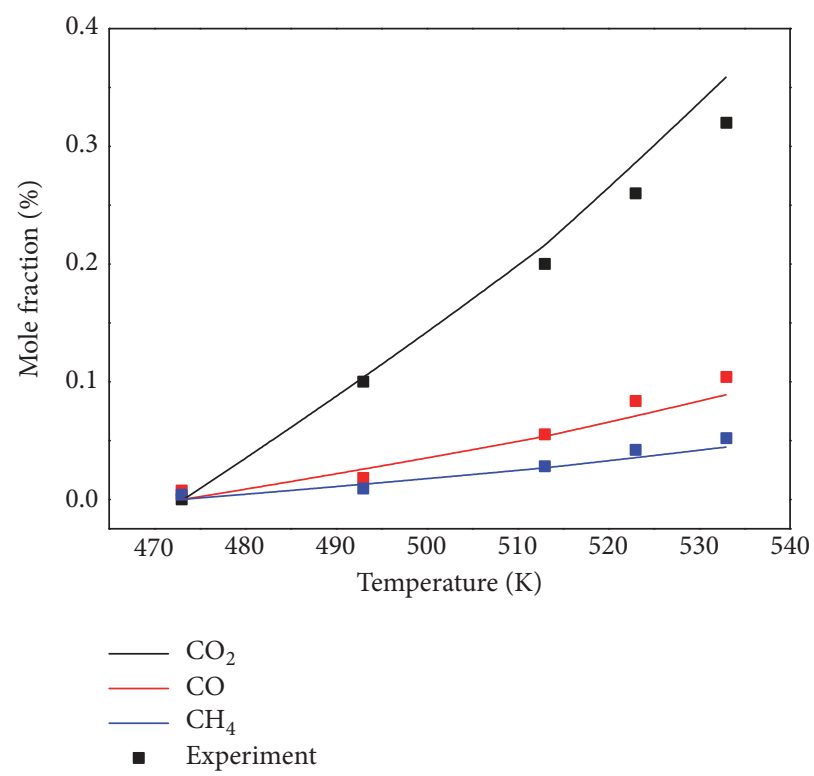

FIGURE 4: The component concentrations of product gas versus temperature.

rpm. The molar fractions of main gas compositions at the exit are shown in Figure 4. In the process of oxidative weight increment, the elevating particle temperature from the wall heat conduction and the heat release of reaction gives rise to the increase of concentrations of exit gas compositions. It can be observed that the predicted values of three kinds of product gas, such as $\mathrm{CO}_{2}, \mathrm{CO}$, and $\mathrm{CH}_{4}$, are basically in agreement with experimental results.

In order to further verify the range of application of the built model, the simulations are performed with a large range of rotation rates, $0.095 \sim 9.5 \mathrm{rpm}$, which take on various forms of solid motion in the rotary kiln. The three representative flow patterns in transverse section and the transition criteria (Froude number and filling degree) characterized by Mellmann [29] are given in Table 4 as the baseline. The contours of predicted solid concentration and particle velocity vector, as well as the criteria number, are illustrated in the last five rows in Table 4 . With regard to the three rotation rates $(0.095,0.95$, and $9.5 \mathrm{rpm})$, the relevant Froude numbers, Fr, are the $2.04 \times 10^{-6}, 2.04 \times 10^{-4}$, and $2.04 \times 10^{-2}$, respectively, and the filling degree, $f$, is about 0.11 . According to the transition criteria, the rotary kiln is operated at surging, rolling, and cascading modes, respectively. The flow characteristics revealed by solid volume fraction and velocity vector are consistent with those of reference modes.

In conclusion, the developed 3D numerical model has successfully predicted the hydrodynamic and reaction characteristics, as well as various motion modes for the typical rotary kilns. Therefore, it can be applied to the further study on oxidation stabilization process of coal tar pitch in a rotary kiln.

3.2. Particle Motion Characteristics. Because the oxidative weight increment is a slow oxidation reaction, the simulation of whole temperature rising process consumes considerable computation time. The base case might cost about eight months under the current computational conditions. Therefore, air flow rate and rotating speed are substantially increased to accelerate the oxidation reaction in the sensitivity analysis of parameters. The key parameters of the following simulation are air flow rate, $50 \mathrm{Nm}^{3} / \mathrm{h}$, and rotational speed, $1.43 \mathrm{rpm}$.

In the rotary kiln, the particles located at the bottom move with the kiln wall by viscous friction force between particles and internal wall, and then the inner particles start moving by viscous force among particles. With the rotation of the kiln, particles on the bed top slide down to the bottom, and another circle will begin when these particles move with the kiln wall. Overall, the variation of particle distribution in the rotary kiln slows after a period of time. In the present simulation, the particle movement reaches the quasi-stable state $5 \mathrm{~s}$ after the initial computation. Figure 5 illustrates the profiles of particle volume fraction in the cross and vertical sections of the kiln $(t=10 \mathrm{~s})$. It can be observed that particles assemble in a specific region, namely, bed region, which has a local high concentration. The bed surface takes on a typical wave form rather than flat plane in the cross section.

To better display the simulation results inside the kiln, postprocessing coordinate is applied for the data processing. Figure 6 is the coordinate schematic of the cross section of the rotary kiln used in present simulations. The origin of Cartesian coordinate is located at the center of the plane. The $\mathrm{z}$-axis and $\mathrm{y}$-axis of postprocessing coordinate are parallel and perpendicular to the particle bed surface at steady state, respectively. As the nomenclature shown in Figure 6, $v_{s}$ is the actual velocity of particles; $v_{z}{ }^{\prime}$ is the velocity component parallel to the surface and $v_{y}{ }^{\prime}$ is the velocity component normal to the surface; L indicates the full chord of the bed; and $\mathrm{H}$ denotes the central thickness of the particle bed.

Figure 7 illustrates the velocity vector of particles at steady state. The color and arrow represent the magnitude and direction of the velocity, respectively. The magnitude 
TABLE 4: The motion forms of particles in rotary kiln.

\begin{tabular}{|c|c|c|c|}
\hline Motion form & Surging & Rolling & Cascading \\
\hline \multicolumn{4}{|l|}{ Schematic } \\
\hline $\begin{array}{l}\text { Froude number, } F r \\
F r=\omega^{2} R / g\end{array}$ & $0<F r<10^{-4}$ & $10^{-4}<\mathrm{Fr}<10^{-2}$ & $10^{-3}<\operatorname{Fr}<10^{-1}$ \\
\hline $\begin{array}{l}\text { Filling degree, } f \\
f=\varepsilon-\sin \varepsilon \cos \varepsilon\end{array}$ & $f>0.1$ & $f>0.1$ & $f>0.1$ \\
\hline Rotation rate $(\mathrm{rpm})$ & 0.095 & 0.95 & 9.5 \\
\hline \multicolumn{4}{|l|}{$\begin{array}{l}\text { Contours of simulated } \\
\text { solid concentration }\end{array}$} \\
\hline \multicolumn{4}{|l|}{$\begin{array}{l}\text { Contours of simulated } \\
\text { particle velocity vector }\end{array}$} \\
\hline Froude number, $\mathrm{Fr}$ & $2.04 \times 10^{-6}$ & $2.04 \times 10^{-4}$ & $2.04 \times 10^{-2}$ \\
\hline Filling degree, $f$ & 0.11 & 0.11 & 0.11 \\
\hline
\end{tabular}

increases from the blue to red. From the vector contour and partial enlargement in the middle, it can be seen that two particle layers with opposite direction of velocity exist in the bed. The downward velocity in the upper layer is obviously larger than in the lower layer, improving the performances of mixing and heat transfer between gas and particle phases. This thin layer is called the active layer [6]. The particles in the lower layer are stacked and move upward with the kiln by the friction. The small relative velocity in this thick layer leads to the weak particles mixing and heat transfer, which is called the passive layer [6]. As displayed in left and middle drawings of partial enlargement, the particle velocity vector at the bed surface is at an angle rather than being parallel to the surface. Because of the particles collision, the particles in the outer layer bounce from the surface and drop by gravity, resulting in the velocity component normal to the surface. In the bottom region of bed surface (enlarged figure on the right), some particles could bounce off after their collision with kiln wall. These simulation results are in accordance with the data in [30].

The variation of particle velocity with the bed depth is presented in Figure 8(a). Owing to similarity of profile shapes irrespective of the position along the chord length, the detailed analysis focuses on the results at mid-chord position
[28]. It can be observed that the greatest velocity and velocity gradient appear on surface of the active layer. As the bed thickness $\left(y_{f}^{\prime}\right.$, distance from surface) increases, the particle velocity dramatically decreases and reaches zero when the dimensionless thickness of the layer $\left|y_{f}^{\prime} / \mathrm{H}\right|$ approaches 0.45 . As the bed thickness increases to more than $45 \%$ of the total thickness $\left(\left|y_{f}^{\prime} / \mathrm{H}\right|>0.45\right)$, the particles start moving in the opposite direction, and the velocity gradient gradually reduces. When the bed thickness is larger than $80 \%\left(\left|y_{f}^{\prime} / \mathrm{H}\right|>\right.$ 0.8 ), the particle velocity is basically the same as the wall rotational speed $\left(v_{s} / \omega R=1\right)$. The reason for this is the particles in near-wall region move with the kiln wall due to friction. The variation of particle velocity with different axial lengths of kiln can also be seen in Figure 8(a). With the increase of axial length, the particle velocity gradually decreases, but the change is very small. The slightly larger velocity at $\mathrm{x}=0.05 \mathrm{~m}$ is on account of the little effect of particles on the far left side of the kiln. The minimum velocity on the far right side $(x=0.75$ m) might be ascribed to impact of particles in the region of circular truncated cone. The profiles of particle velocity on bed surface are illustrated in Figure 8(b). Along the $z^{\prime}$ direction, the particle velocity first gradually increases and then decreases. The peak velocity is located at $\mathrm{z}^{\prime} / \mathrm{L}=0.7$, which is the synergy of gravity and solid friction force. Meanwhile, 


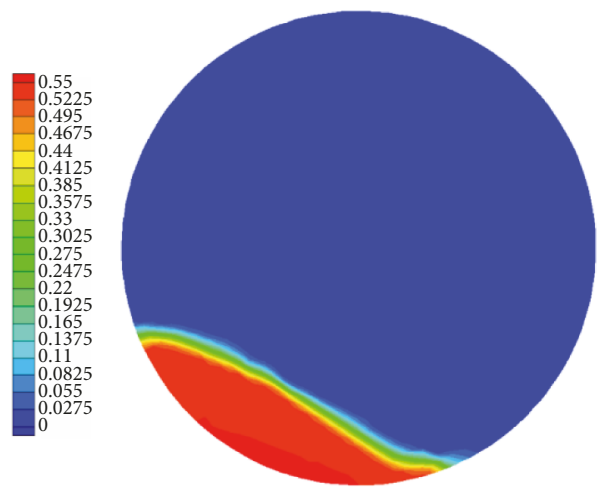

(a)

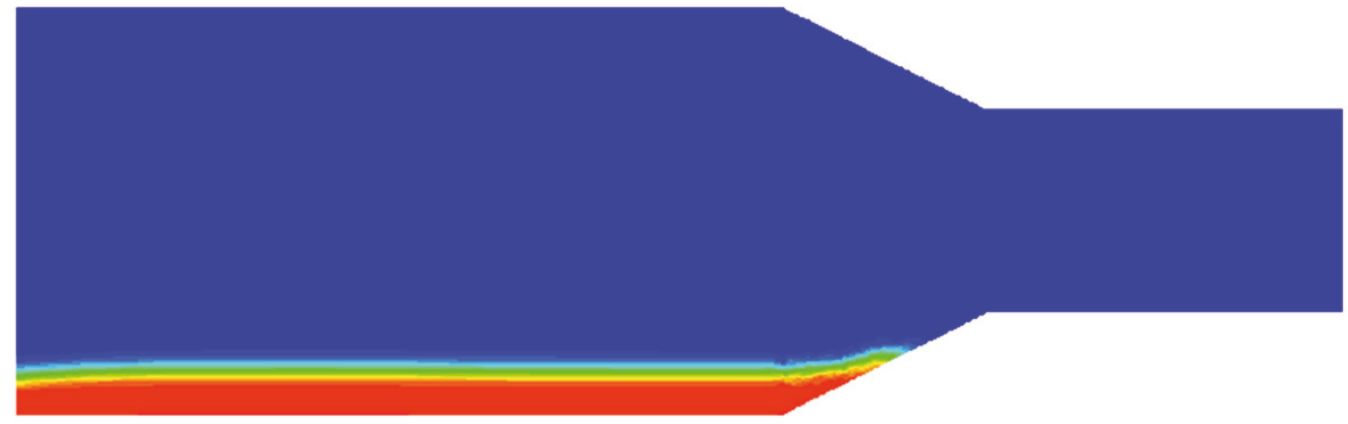

(b)

FIGURE 5: Profiles of solid concentration: (a) cross section; (b) longitudinal section.

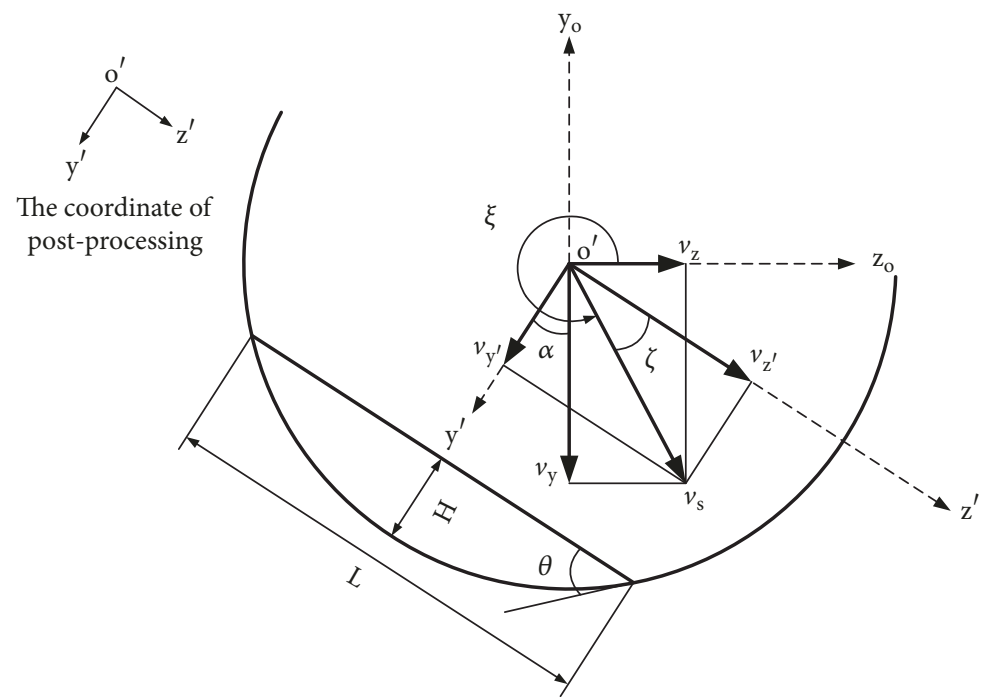

FIGURE 6: The postprocessing coordinate in the rotary kiln.

the particles at the larger axial length have higher velocity in the upper surface region, while are of smaller velocity in the lower region.

3.3. Oxidation Reaction Characteristics. Figure 9 shows the temperature profile of gas phase in the different cross-sections. The temperature contours in the cross section of $\mathrm{x}=0.375 \mathrm{~m}$ and in the longitudinal section of $\mathrm{z}=0 \mathrm{~m}$ are illustrated in Figures 9(a) and 9(b), respectively. It can be observed that the bed region generally has a higher temperature due to the large thermal capacity. The central region is the freeboard where the inlet air with low temperature mainly 


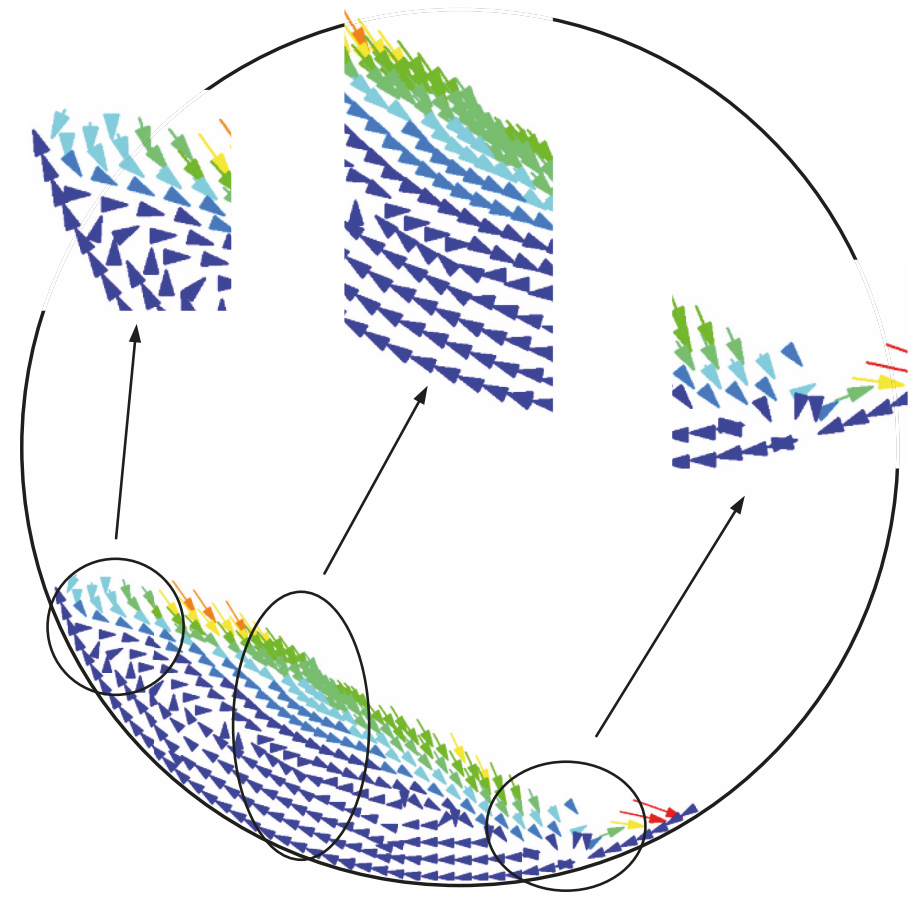

FIGURE 7: Velocity vector contour of particles.

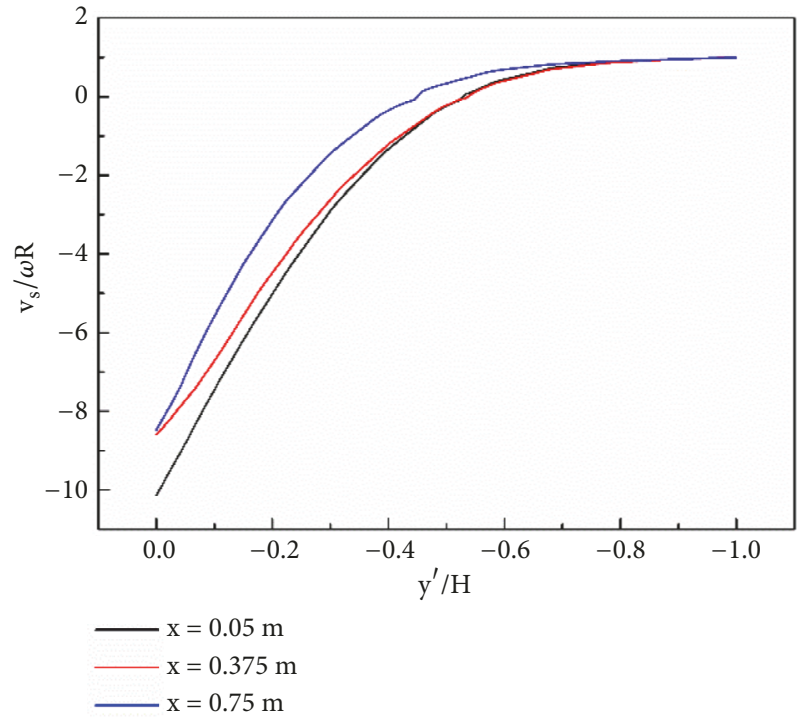

(a)

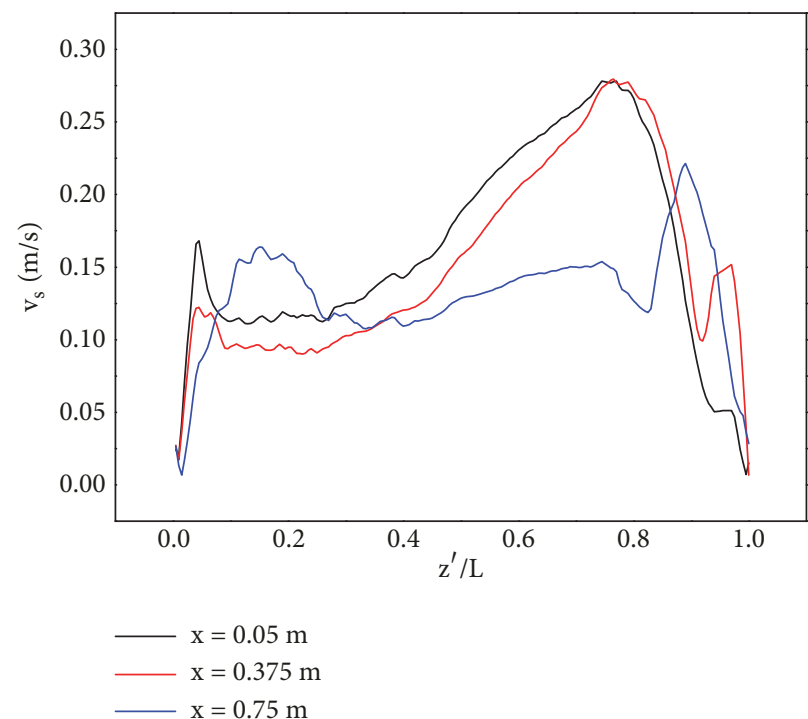

(b)

FIGURE 8: Particle velocity along different directions: (a) depth direction; (b) surface direction.

gathers, so the gas temperature is relatively low. Close to the bed surface, the temperature increases sharply and reaches peak value at bed surface. That is because oxidation reaction firstly takes place in this region. In the passive layer region, the temperature remains stable, and then slightly increases near the cylindrical wall of the rotary kiln due to the wall heat flux. For the different axial positions, because the entering air with low-temperature gathers in the cylindrical region, the gas temperature in the front of the kiln is lower than in the rear.
The distributions of solid temperature in the cross section and in the longitudinal section are illustrated in Figures 10 (a) and $10(\mathrm{~b})$, respectively. The temperature profiles of solid phase are generally in accordance with those of gas phase, except for the peak value. The solid temperature at the bed surface is lower than gas temperature, and no obvious peak exists for the solid phase. The discrepancy of physical property gives rise to the higher temperature rise for the gas phase. It is worth noting that the particles with solid volume fraction of less than 0.01 are 


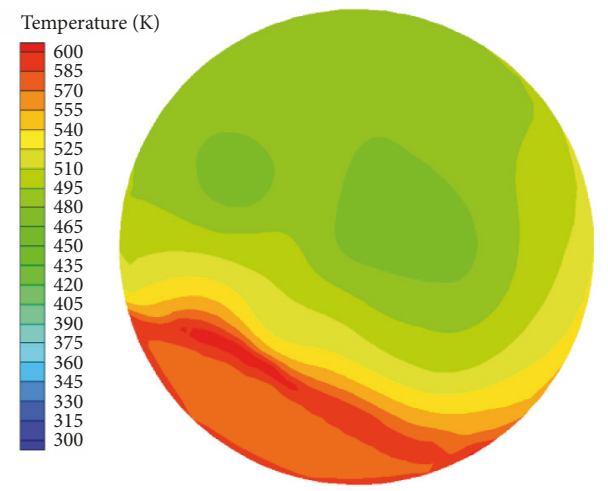

(a)

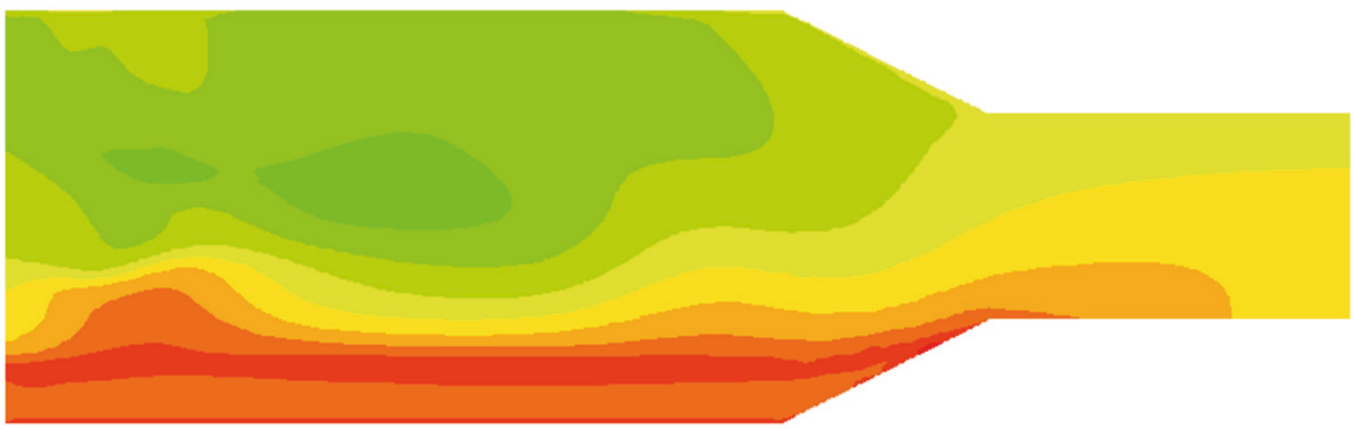

(b)

FIGURE 9: Temperature profiles of gas phase: (a) cross section; (b) longitudinal section.

neglected so the bed surface in the figure is not very smooth.

Figures 11-14 illustrate the concentration profiles of four main gas compositions, namely $\mathrm{O}_{2}, \mathrm{CO}_{2}, \mathrm{CO}$, and $\mathrm{CH}_{4}$. As shown in Figure 11, $\mathrm{O}_{2}$ primarily gathers in the freeboard region, and decreases suddenly at the bed surface due to oxidative reaction. When entering the bed region, the $\mathrm{O}_{2}$ concentration almost approaches zero, because high concentration of coal pitch sphere leads to the huge consumption of $\mathrm{O}_{2}$. Along the axial direction, the $\mathrm{O}_{2}$ concentrations in the cylindrical region $(x<0.75 \mathrm{~m})$ are apparently higher than in the back of the kiln $(x>0.75 \mathrm{~m})$ as a result of the gas diffusion and oxidative reaction. The middle section of cylinder has highest $\mathrm{O}_{2}$ concentration in the freeboard region, as a result of the inlet air gathering. As a product of oxidation reactions, $\mathrm{CO}_{2}$ concentration takes on a nearly opposite profile of the reactant of $\mathrm{O}_{2}$, as shown in Figure 12. That is, $\mathrm{CO}_{2}$ molar fraction has a low value in freeboard region, and then increases sharply close to bed surface, and finally remains stable inside the bed. The $\mathrm{CO}_{2}$ concentrations in the cylindrical region of the kiln are apparently lower than in the back, and the middle of cylinder is of minimal $\mathrm{CO}_{2}$ concentration in the freeboard. In Figures 13 and 14, the concentration profiles of $\mathrm{CO}$ and $\mathrm{CH}_{4}$ have the similar variation trends with that of $\mathrm{CO}_{2}$, the only difference existing in the magnitude of concentration. As can be seen from
Figures 11-14, a circular truncated cone is located at right side $(\mathrm{x}=0.75 \sim 0.95 \mathrm{~m})$ and connected to a cylinder with 0.2 $\mathrm{m}$ diameter $(\mathrm{x}>0.95 \mathrm{~m})$. The product gas such as $\mathrm{CO}_{2}, \mathrm{CO}$, and $\mathrm{CH}_{4}$ tends to concentrate in the exit section, while the air is of lower concentration in this region. However, since the coal pitch particles are concentrated at the bottom of the reactor (Figure 5(b)), the locally uniform distribution of gas components caused by the geometry has little impact on the oxidation process.

The contours of concentration profile for oxidized coal tar pitch in the cross section and longitudinal section are shown in Figure 15. It should be noted that the color in the figure presents the mass fraction of the oxidized coal pitch. In general, the higher concentration of oxidized coal pitch exists at the top of the bed because of the elevated temperature and plenty of oxygen. Since the coal tar pitch sphere assembles in the bed region, the mass fraction of oxidized coal pitch approaches to zero in the freeboard region. At the bed surface, the concentration of the oxidized yield of coal tar pitch increases suddenly and keeps on a steady value in the passive layer region. The profiles of solid concentration along the axial position are similar to those of gas phase. Considering the high concentrations of $\mathrm{O}_{2}$ in the middle region, and the $\mathrm{O}_{2}$ consumption along the axial distance due to oxidation reaction, the mass fraction of oxidized coal pitch in the front of the kiln is larger than in the rear. 


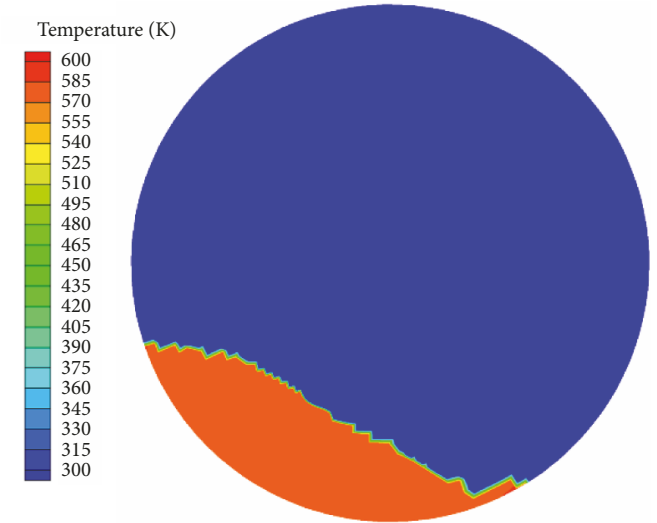

(a)

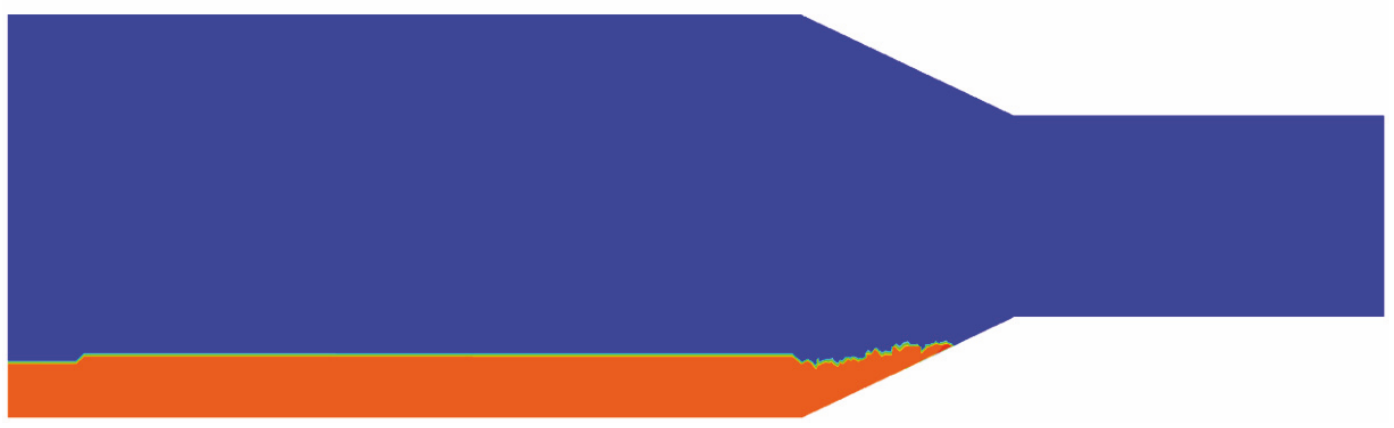

(b)

FIGURE 10: Temperature profiles of solid phase: (a) cross section; (b) longitudinal section.
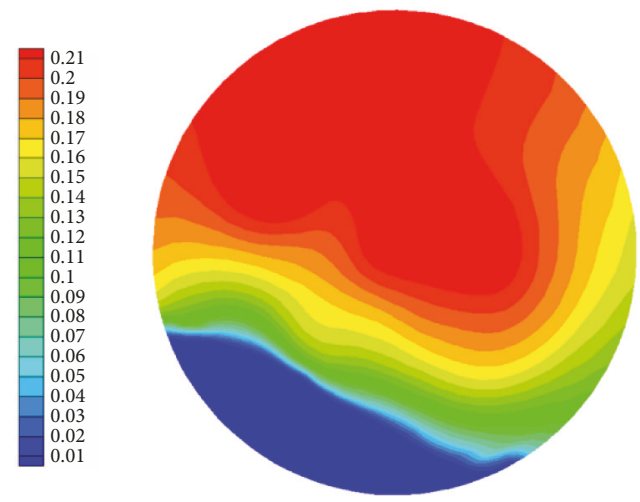

(a)

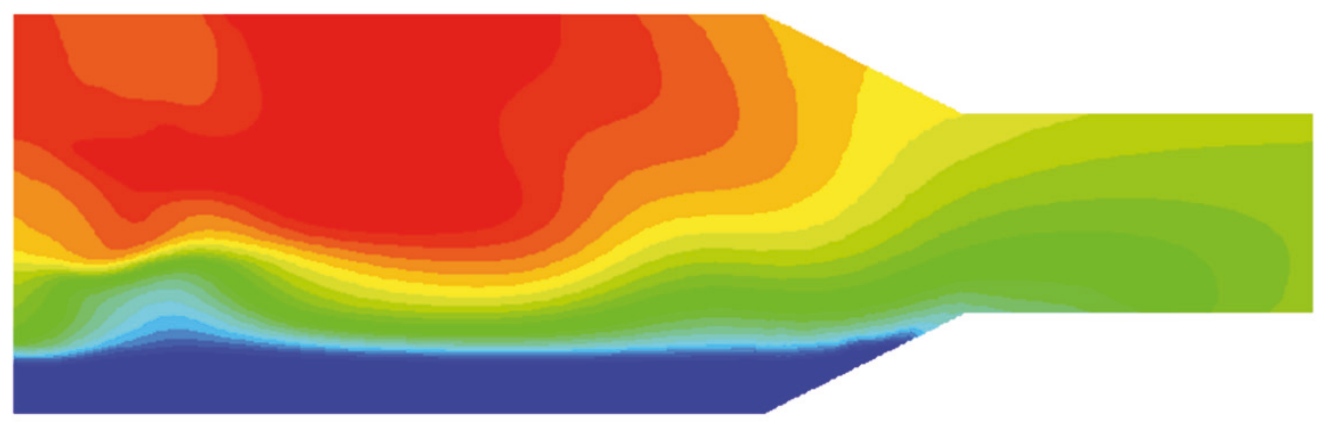

(b)

FIGURE 11: Concentration profiles of $\mathrm{O}_{2}$ : (a) cross section; (b) longitudinal section. 


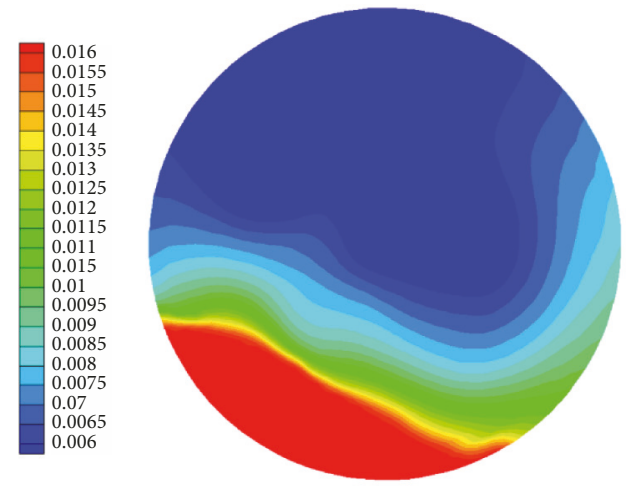

(a)

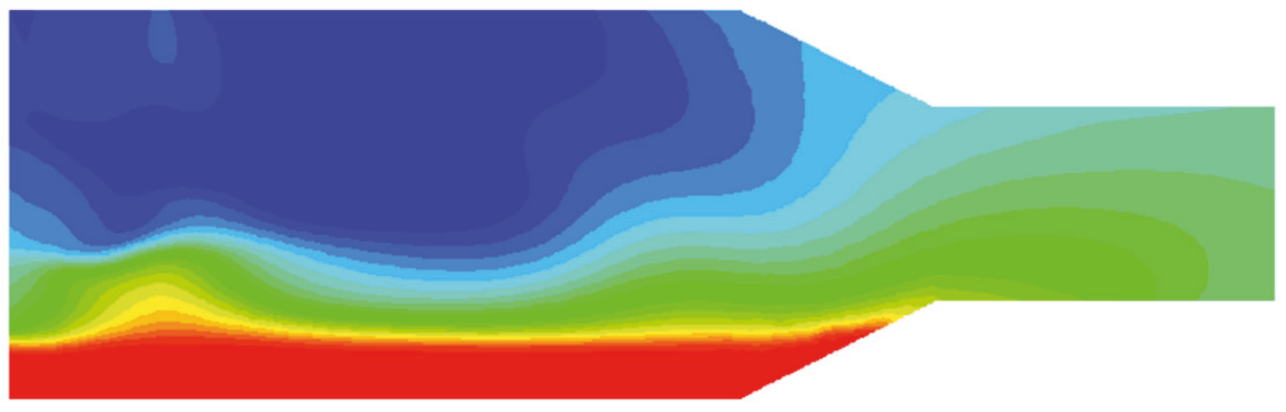

(b)

FIGURE 12: Concentration profiles of $\mathrm{CO}_{2}$ : (a) cross section; (b) longitudinal section.

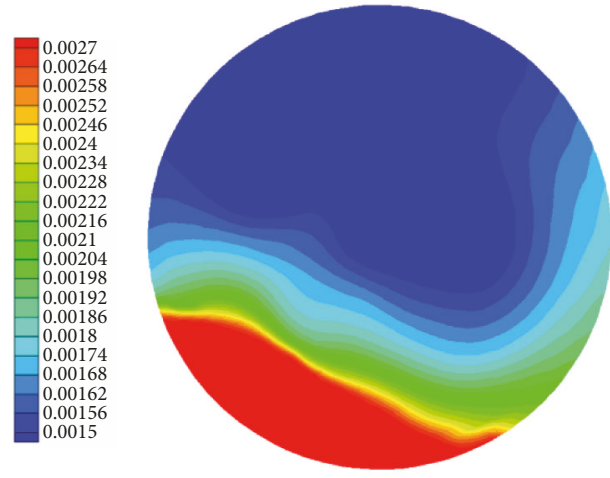

(a)

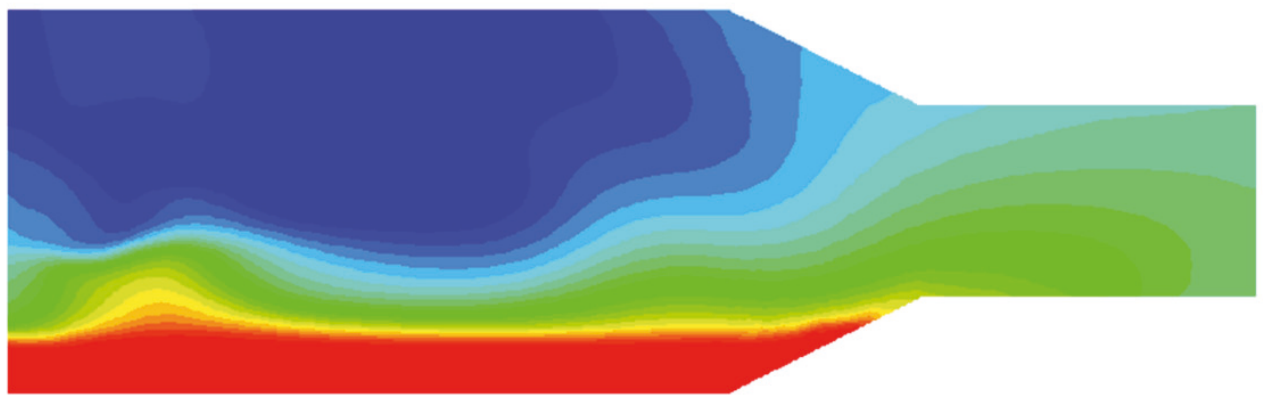

(b)

FIGURE 13: Concentration profiles of CO: (a) cross section; (b) longitudinal section. 


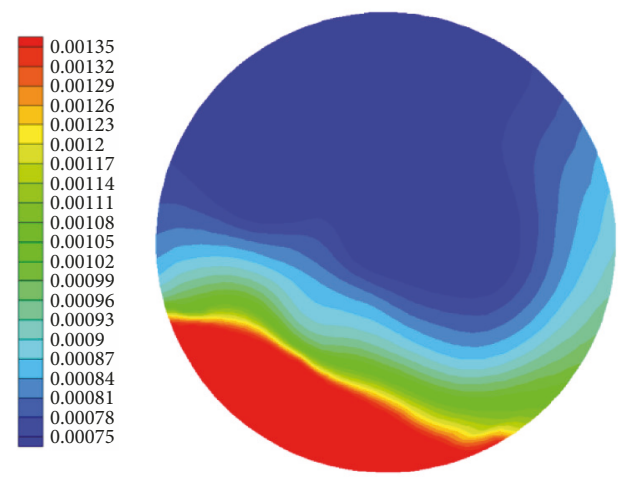

(a)

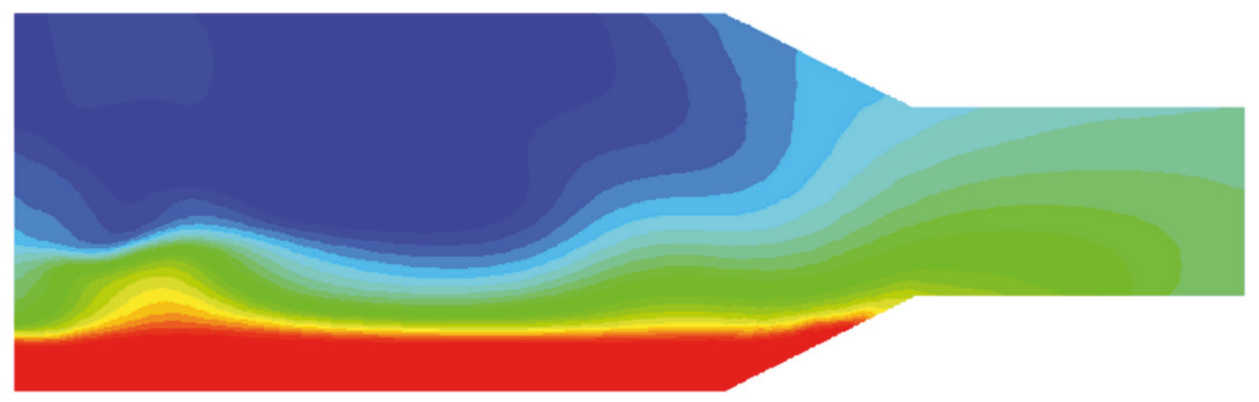

(b)

FIGURE 14: Concentration profiles of $\mathrm{CH}_{4}$ : (a) cross section; (b) longitudinal section.

3.4. Effects of Air Flow Rate and Rotational Speed. To investigate the effects of operating parameters on the gas-solid flow and oxidation reaction characteristics, flow rate of air and rotational speed are changed within a relatively wide range. The particle velocity profiles, temperature profiles of gas and solid, the product gas, and oxidized yield of coal tar pitch are analyzed in the following section.

3.4.1. Effects on Particle Motion. The simulations are performed with air flow rates as $25,37.5,50$, and $62.5 \mathrm{Nm}^{3} / \mathrm{h}$, while the rotating speed remains a constant value of $1.43 \mathrm{rpm}$. Figure 16 shows the particle velocity profiles along the bed depth and bed surface. As can be seen from Figure 16(a), when $\left|y^{\prime} / H\right|>0.7$, the four curves with the different air flow rates basically coincide, and the particle velocity of the passive layer approaches the rotation speed of the kiln. The profile shapes of particle velocity on the bed surface are roughly the same under different air flow rates. These curves in Figure 16(b) present slightly skewed parabola, and the maximum velocity occurs at about $\mathrm{z}^{\prime} / \mathrm{L}=0.75$. In general, there is no definite tendency for the particle velocity with the increasing air flow, indicating that air flow rate has little impact on the particles motion.

Figure 17 shows the variations of particle velocities with various rotating speeds. The kiln is rotated with the speeds of $0.95,1.43,1.91$, and $2.39 \mathrm{rpm}$, and the flow rate of air is kept at
$50 \mathrm{Nm}^{3} / \mathrm{h}$. It is evident from Figure 17 (a) that the rotational speed has a significant impact on the particle velocity along the depth direction. When the rotational speed increases from 0.95 to $2.39 \mathrm{rpm}$, the particle velocity of the active layer increases from eight times the tangential wall velocity $(\omega R)$ to thirteen times the velocity, and the thickness of the active layer is also found to increase correspondingly. The increase in the rotational speed encourages more particle participation in the circular reciprocating movement of the outer layer per unit time and accelerates the update frequency of surface particles. Figure 17(b) shows that the particle velocity along the bed surface also increases with the increasing rotational speed. When the speed increases within the range of $0.95 \sim$ $2.39 \mathrm{rpm}$, the maximum particle velocity at bed surface gradually increases until it reaches $0.65 \mathrm{~m} / \mathrm{s}$. In addition, the increasing rotational speed gives rise to the profile of surface velocity shift towards the center of the chord $\left(z^{\prime} / L=0.5\right)$, and the parabolic shape is more symmetric. In conclusion, the increase of rotating speed can significantly increase the movement speed of particles and thicken the active layer, which is conducive to the mixing and replacement of particles in the kiln.

3.4.2. Effects on Gas and Solid Temperature. Figure 18 shows the distributions of gas and particle temperature along the negative $y^{\prime}$ axis and central cross section of the rotary kiln 


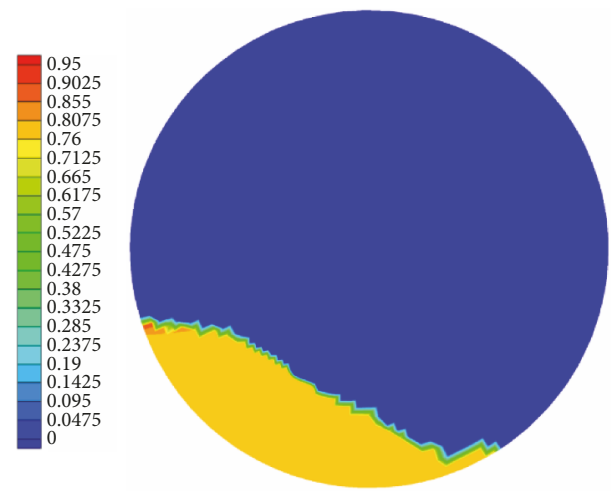

(a)

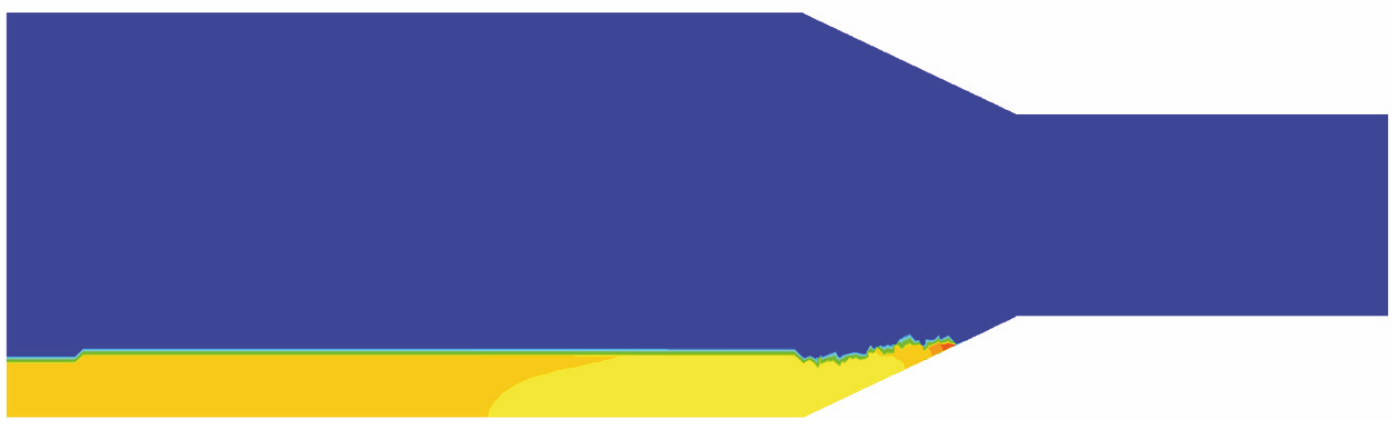

(b)

FIGURE 15: Concentration profiles of oxidized coal pitch: (a) cross section; (b) longitudinal section.

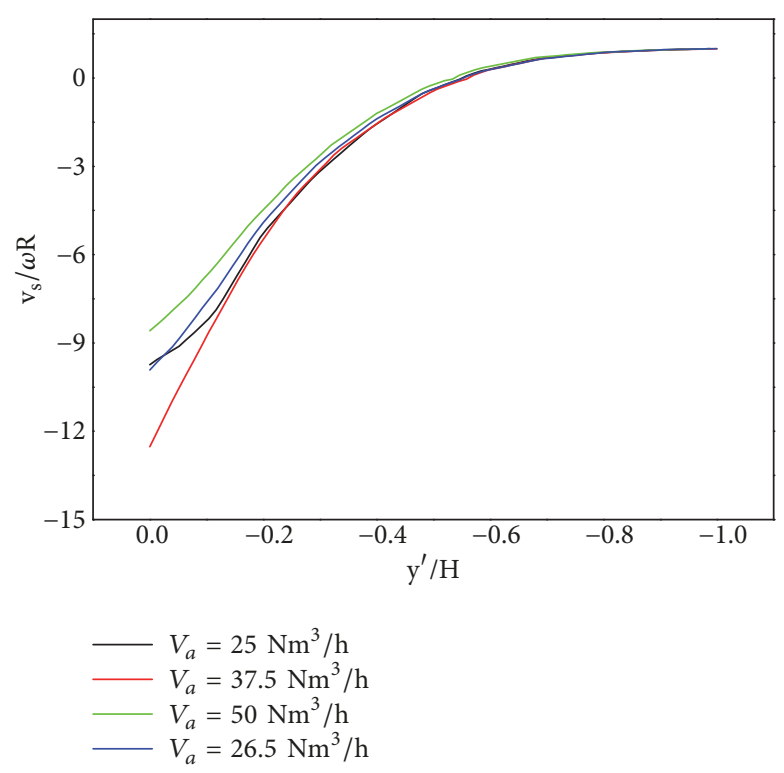

(a)

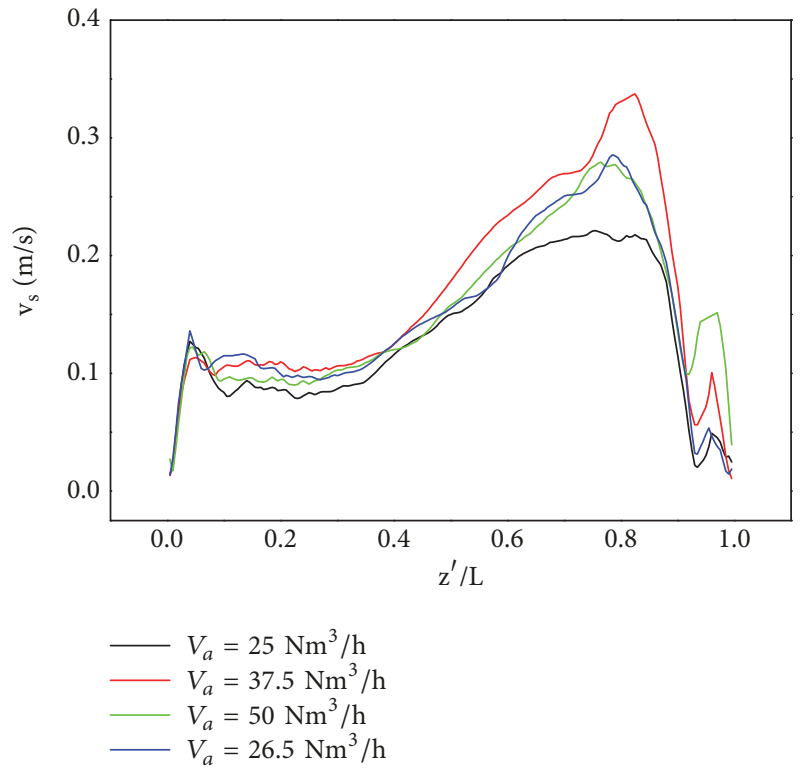

(b)

FIGURE 16: Particle velocity profiles at various air flow rates: (a) depth direction; (b) surface direction.

$(\mathrm{x}=0.375 \mathrm{~m})$ under different air flow rates with a constant rotational speed of $1.43 \mathrm{rpm}$. It can be found that the gas temperature is lower in the freeboard region and higher in the bed region. The temperature gradient is obviously large near the active layer region, where oxygen is well mixed with the coal pitch sphere, promoting the oxidation reaction. The gas temperature is rapidly heated by releasing heat, and the maximum value appears in this region. By contrast, the temperature profile of the particle phase remains stable throughout the bed surface, where the particle temperature is 


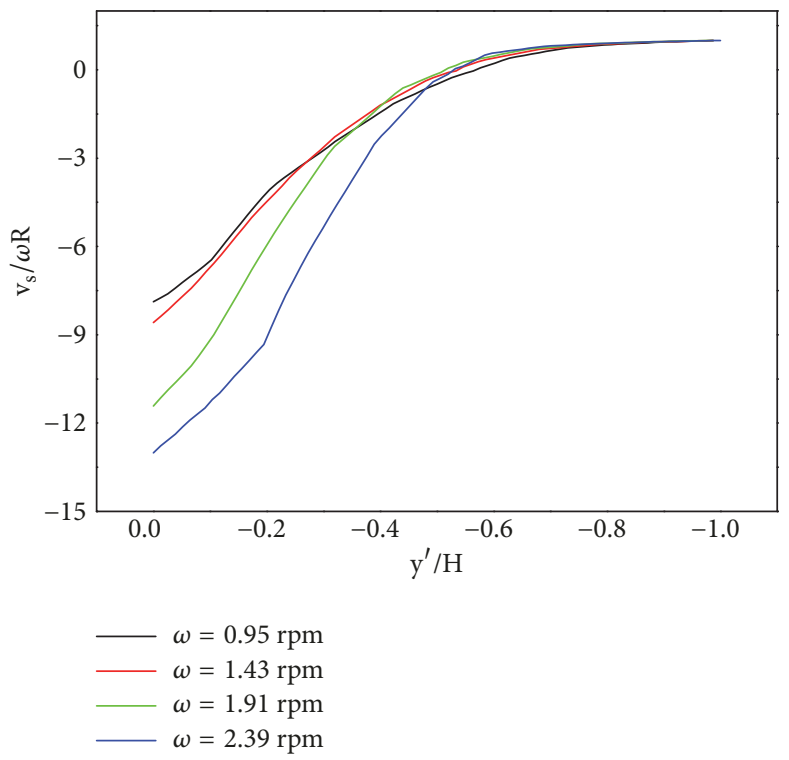

(a)

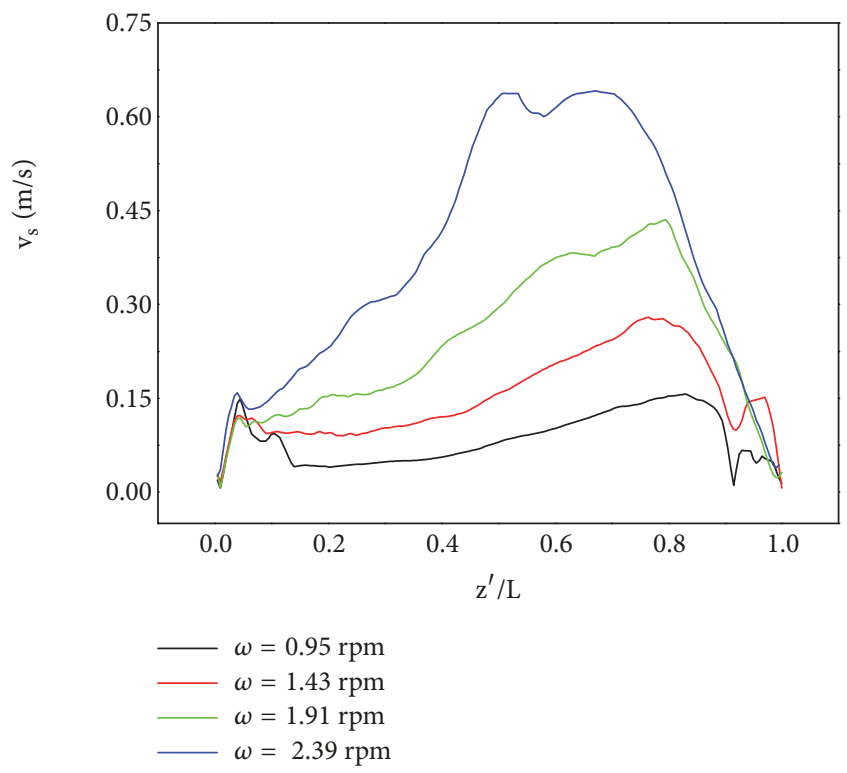

(b)

FIGURE 17: Particle velocity profiles at various rotational speeds: (a) depth direction; (b) surface direction.

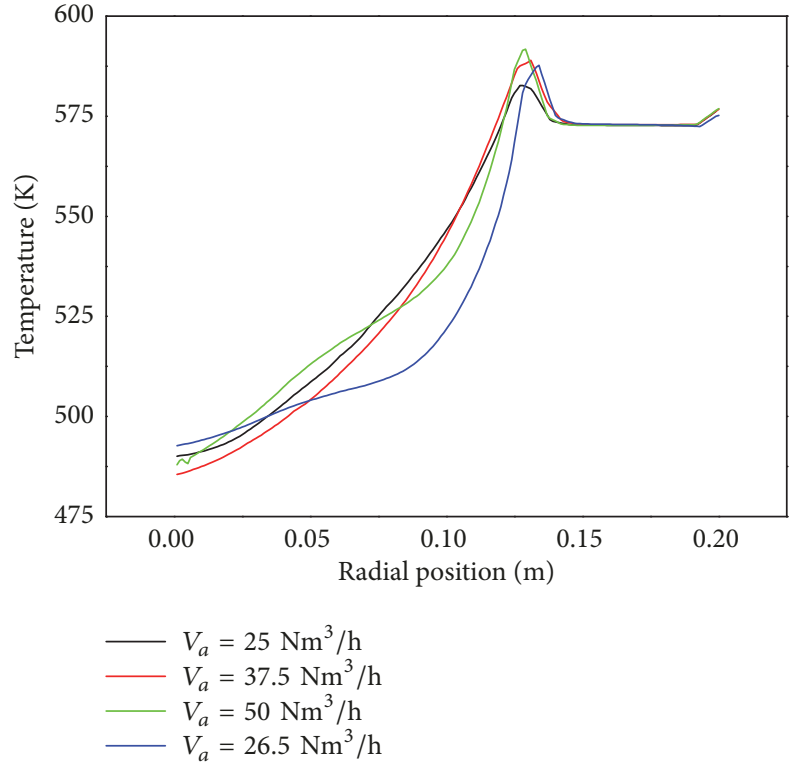

(a)

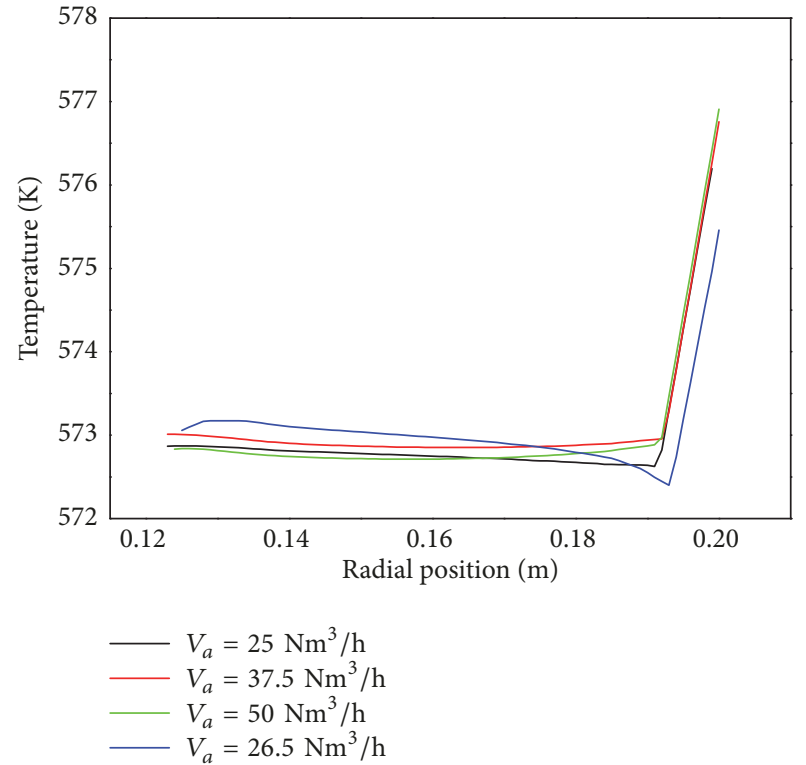

(b)

FIGURE 18: Profiles of gas and particle temperatures at various air flow rates: (a) gas phase; (b) solid phase.

lower than that of gas phase. The slightly higher temperature of solid phase lies in the wall region of the rotary kiln due to wall heat flux, which also takes on for the gas phase. Under different air flow rates, the temperature profiles of gas and particles basically overlap in the passive layer, only slight differences existing in the freeboard and the active layer. It shows that air flow rates have no obvious influence on the temperature distributions of gas and particles in rotary kiln. Although the increasing inlet air introduces more low-temperature gas, the higher oxygen concentration facilitates the oxidation reaction, which means more heat released from the reaction compensates for the effects of cold air.

Figure 19 shows the temperature distributions of gas and particle phases along the negative $y^{\prime}$ axis at different rotational speeds with the same air flow rate of $50 \mathrm{Nm}^{3} / \mathrm{h}$. It can be found that the rotational speed also has no definite effect on the temperature profile in the freeboard, while some tendency being in the active layer and near-wall regions. With the increase of rotational speeds, the temperature of gas and solid 


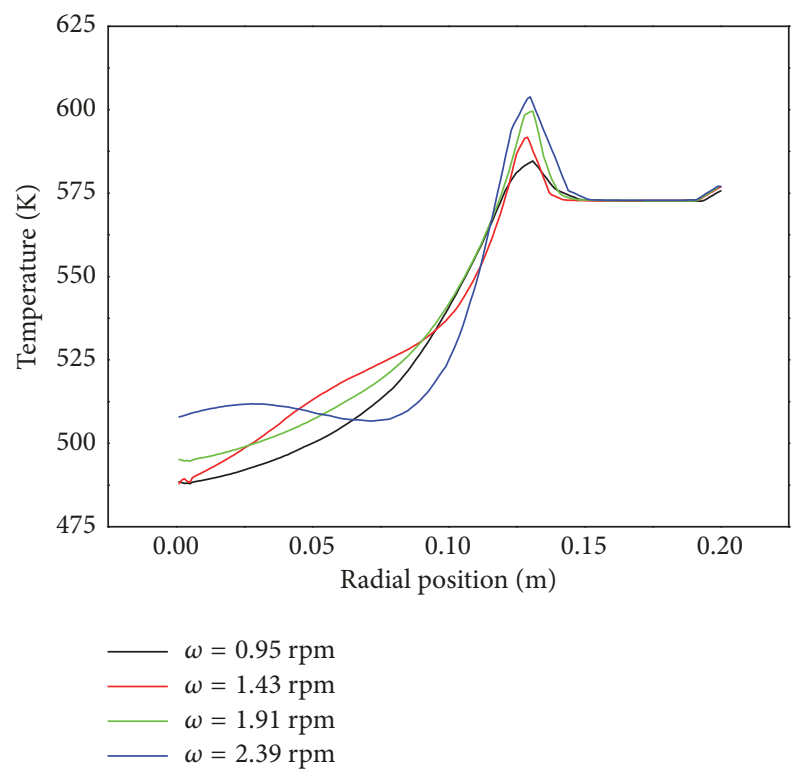

(a)

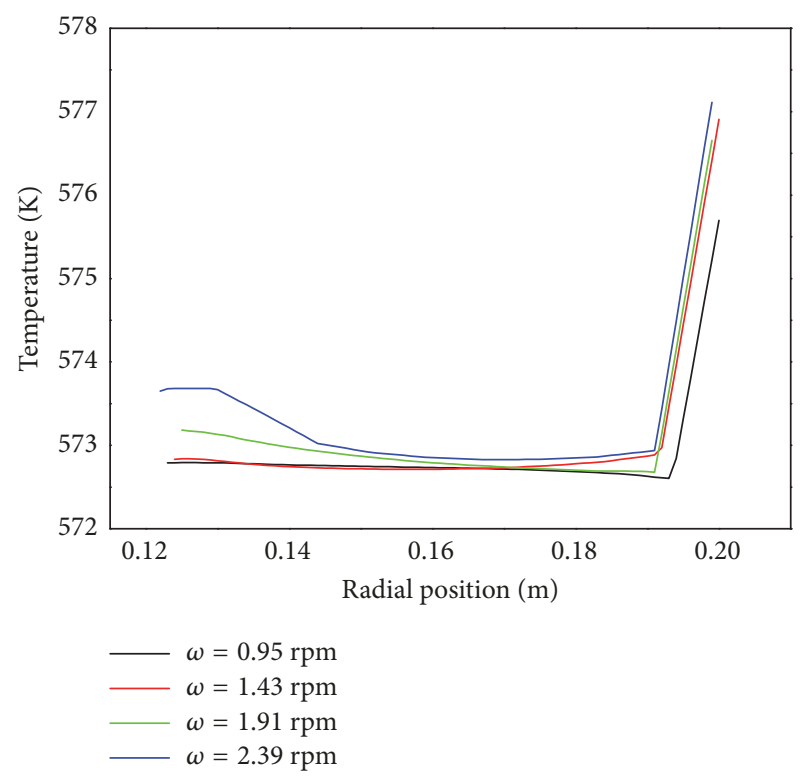

(b)

FIGURE 19: Profiles of gas and particle temperatures at various rotational speeds: (a) gas phase; (b) solid phase.

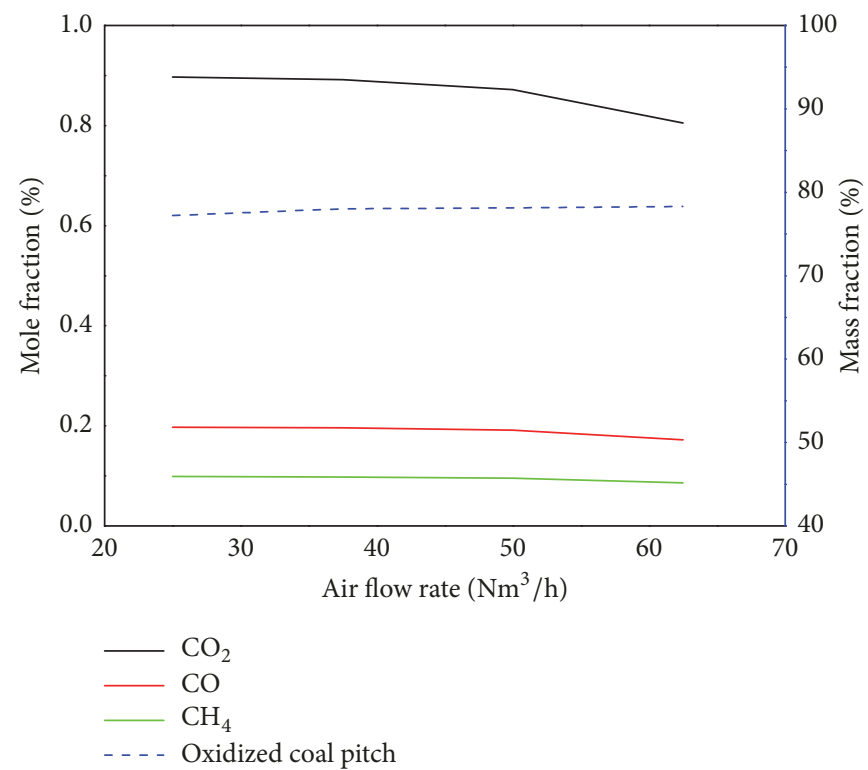

(a)

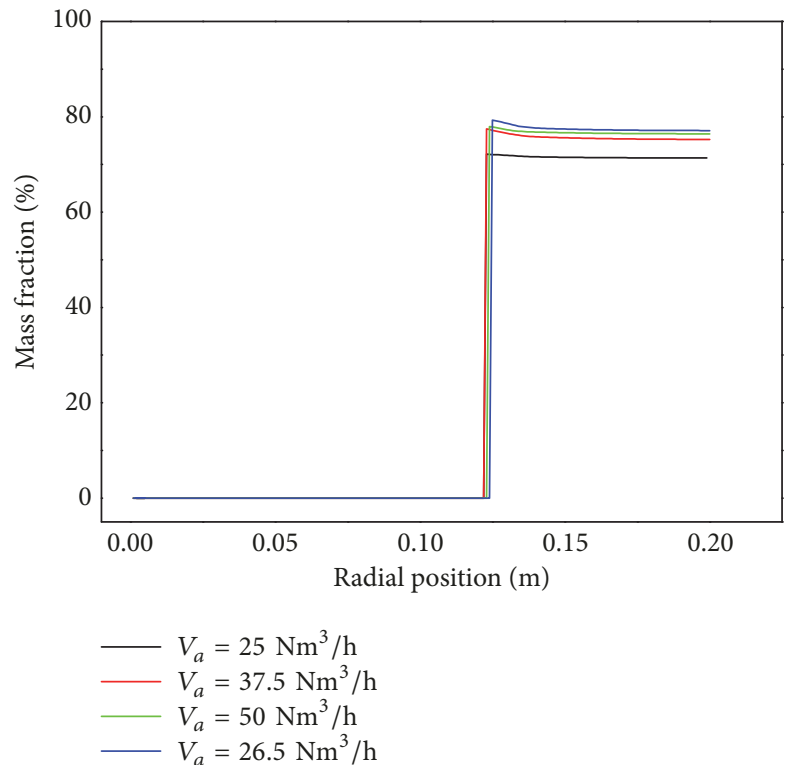

(b)

FIGURE 20: Concentrations of product gas and solid versus air flow rate: (a) product gas and solid; (b) radial concentration of solid.

phases gradually increases at the bed surface and near the wall, but only to a small extent.

3.4.3. Effects on Product Gas and Oxidized Coal Pitch. The variations of product gas and solid with air flow rate are shown in Figure 20(a). The flow rates of air increase between 25 and $62.5 \mathrm{Nm}^{3} / \mathrm{h}$, while the rotational speed remains the same value of $1.43 \mathrm{rpm}$. The calculated results of gas molar fraction adopt the form of area average at the outlet, while the mass fraction of oxidized coal tar pitch is the value of the whole kiln. With the increase of air flow rate, more $\mathrm{O}_{2}$ takes part in the reaction. The accelerated rate of oxidation reaction gives rise to the increase of quantities of generated gas and solid. Therefore, the mass fraction of oxidized coal pitch slightly increases with the increasing air flow rate. However, the increasing flow rate of air introduces a large amount of $\mathrm{N}_{2}$, which has a dilution effect on the product gas and counteracts the effect of accelerated oxidation reaction. It can been seen from Figure 20(a), concentrations of three product gas compositions, such as $\mathrm{CO}_{2}, \mathrm{CO}$, and $\mathrm{CH}_{4}$, present a dropping trend to various degrees when the air flow rate increases. 


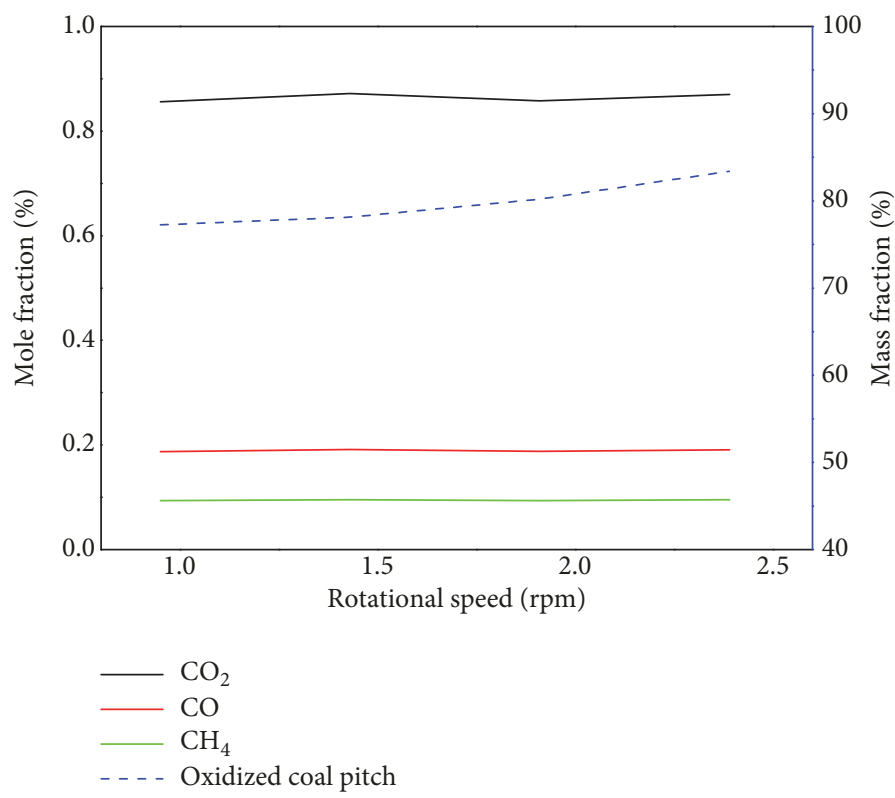

(a)

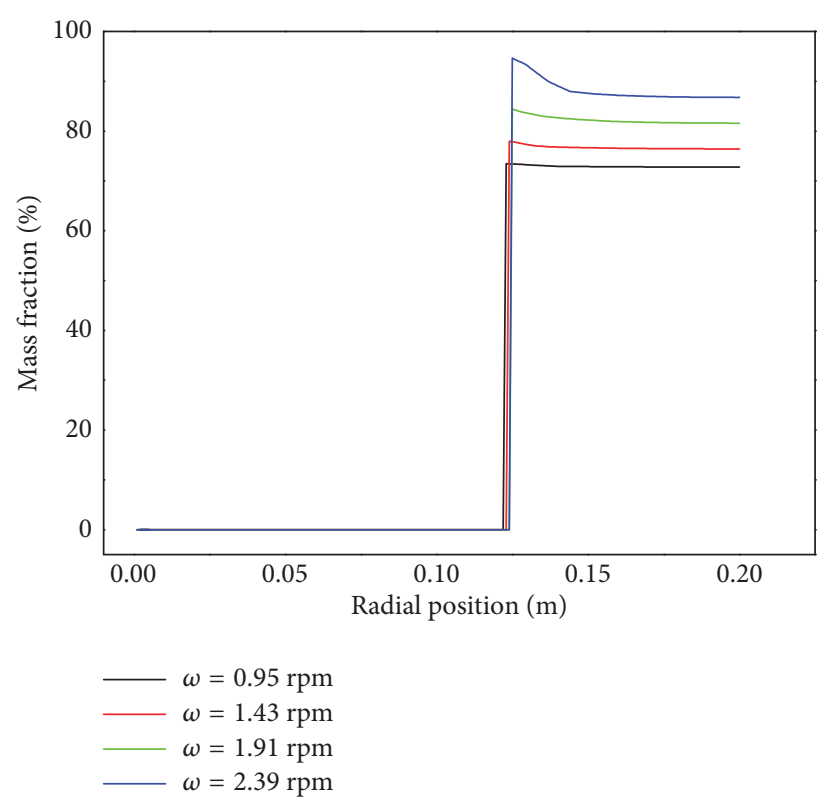

(b)

FIGURE 21: Concentrations of product gas and solid versus rotational speed: (a) product gas and solid; (b) radial concentration of solid.

The effects of air flow rate on radial concentration profiles of the oxidized yield of coal tar pitch are illustrated in Figure 20(b). Along the radial position, the mass fraction of oxidized coal pitch has an abrupt increase and reaches its peak near the bed surface because of the higher temperature and $\mathrm{O}_{2}$ concentration. As the flow rate of air increases, more oxidation reaction takes place and the oxidized yield of oxidized coal pitch gradually increases in the bed region.

Figure 21 shows the variations of product gas and solid with rotating speed. The kiln is rotated with the speeds of $0.95,1.43,1.91$, and $2.39 \mathrm{rpm}$, and the flow rate of air is kept at $50 \mathrm{Nm}^{3} / \mathrm{h}$. As the rotating speed increases, the contact area and time between air and coal pitch sphere increase, which effectively enhances the oxidation reaction. Therefore, the final oxidative yield of coal pitch spheres increases with the increasing rotating speed. The concentrations of main product gas, including $\mathrm{CO}_{2}, \mathrm{CO}$, and $\mathrm{CH}_{4}$, are almost the same because the gas dilution offsets the accelerated oxidation.

The radial concentration profiles of oxidized coal pitch at different rotational speeds are presented in Figure 21(b). When the rotational speed increases, the oxidized yield of coal tar pitch in the bed region and the peak value on the bed surface gradually increase due to the enhanced oxidation reaction. Because fewer discrete particles appear above the bed surface and bed thickness reduces with the increasing rotational speed, the radial position of abrupt increase of oxidized coal pitch slightly moves backward.

\section{Conclusions}

In this paper, the two-fluid method and kinetic theory of granular flow are combined with heat transfer and reaction, which is applied to simulate the process of oxidative weight increment of coal tar pitch in a rotating kiln. The dense gassolid motion, heat transfer, and chemical reaction for the entire regions of the kiln are simultaneously solved. Based on the model validation, the simulations are carried out to give the detailed particle movement and reactive characteristics in the $3 \mathrm{D}$ space. The effects of air flow rate and rotating speed on the profiles of particle velocity and gas-solid temperature, the exit gas composition, and oxidized coal pitch are also studied. The primary conclusions can be drawn as follows:

(1) The developed 3D numerical model has successfully predicted the hydrodynamic and reaction characteristics, as well as various motion modes (surging, rolling, and cascading mode) for the typical rotary kilns. The calculated results are consistent with experimental data.

(2) After reaching a steady state, a wave shape forms on the bed surface. Due to the particles collision, the particle velocity vector is not parallel to the surface. The particle velocity peak is located at the active layer surface and dramatically decreases along the bed thickness, after that the particle velocity turns into opposite direction in the passive layer.

(3) The bed region generally has a higher temperature than the freeboard due to the large thermal capacity. The highest gas temperature exists at the bed surface, and the temperature remains stable in the passive layer region. No obvious peak of temperature exists for the solid phase. Meanwhile, the gas and solid phases have slightly higher temperatures near the wall of the rotary kiln.

(4) The main compositions of product gas include $\mathrm{CO}_{2}$, $\mathrm{CO}$, and $\mathrm{CH}_{4}$, and the generated solid species is the 
oxidized coal pitch. The concentrations of gas product and oxidized coal tar pitch increase sharply near the surface and then keep on a steady value in the passive layer region.

(5) There is no definite tendency for the particle velocity with the increasing air flow rate. By contrast, the increase of rotating speed can significantly accelerate the particle movement and increase the thickness of active layer, which is conducive to the mixing and replacement of particles in the kiln.

(6) The air flow rate has no obvious influence on the temperature profiles of gas and particles inside the rotary kiln. With the increase of rotational speeds, the temperatures of gas and solid phases have an increasing trend at the bed surface and near the wall, but only to a small extent.

(7) The increasing rotational speed effectively enhances the oxidation reaction. The final oxidative yield of coal pitch spheres increases with the rotational speed, while the concentrations of product gas compositions, such as $\mathrm{CO}_{2}, \mathrm{CO}$, and $\mathrm{CH}_{4}$, are almost the same because of the gas dilution. In comparison, increasing the flow rate of air has little effect on the particle motion and oxidation yield of coal tar pitch.

\section{Nomenclature}

A: Preexponential constant

$C_{D}$ : Drag coefficient

$d_{s}$ : Particle diameter, $\mathrm{mm}$

$D_{g s}$ : Diffusion coefficient for gas $\left(\mathrm{m}^{2} / \mathrm{s}\right)$

$E$ : Activation energy

$g_{0}$ : Radial distribution function

$h$ : Heat transfer coefficient $\left(\mathrm{W} / \mathrm{m}^{2} \cdot \mathrm{K}\right)$

$h_{w}$ : Wall heat flux $\left(\mathrm{W} / \mathrm{m}^{2}\right)$

$H$ : Specific enthalpy $(\mathrm{J} / \mathrm{kg})$

$J_{i}$ : The diffusion flux $\left(\mathrm{kg} / \mathrm{m}^{2} \cdot \mathrm{s}\right)$

$k$ : Turbulent kinetic energy $\left(1 / \mathrm{m}^{2} \cdot \mathrm{s}^{2}\right)$

$m$ : Mass $(\mathrm{kg})$

$\mathrm{Nu}$ : Nusselt number

p: $\quad$ Pressure $(\mathrm{Pa})$

Pr: Prandtl number

$Q_{\mathrm{f}}: \quad$ Fuel feed rate $(\mathrm{kg} / \mathrm{h})$

$r: \quad$ Reaction rate $\left(\mathrm{kmol} / \mathrm{m}^{3} \cdot \mathrm{s}\right)$

$R: \quad$ Universal gas constant $(\mathrm{J} / \mathrm{kmol} \cdot \mathrm{K})$

$R e$ : Reynolds number

$S: \quad$ Mass source term

$S c_{t}:$ Schmidt number

$T: \quad$ Temperature (K)

$V_{a}$ : Volume flow rate of air $\left(\mathrm{m}^{3} / \mathrm{h}\right)$

$v:$ Gas velocity $(\mathrm{m} / \mathrm{s})$

$Y_{i}$ : Mass fraction.

\section{Greek Letters}

$\alpha$ : Volume fraction

$\beta$ : Gas-solid interphase drag coefficient

$\chi$ : Instantaneous mass fraction of weight increment $\gamma$ : Dissipation of fluctuating energy $\left(\mathrm{W} / \mathrm{m}^{3}\right)$

$\varepsilon$ : Dissipation rate of turbulent kinetic energy $\left(1 / \mathrm{m}^{2} \cdot \mathrm{s}^{3}\right)$

$\lambda$ : Thermal conductivity $\left(\mathrm{W} / \mathrm{m}^{2} \cdot \mathrm{K}\right)$

$\mu$ : Viscosity $(\mathrm{kg} / \mathrm{m} \cdot \mathrm{s})$

$\rho:$ Density $\left(\mathrm{kg} / \mathrm{m}^{3}\right)$

$\tau$ : Stress tensor $(\mathrm{Pa})$

$\omega$ : Rotational speed (rpm).

\section{Subscripts}

g: Gas phase

$i$ : The $i$ th species

l: Laminar flow

$s$ : Solid phase

$t$ : Turbulent flow.

\section{Data Availability}

The data used to support the findings of this study are available from the corresponding author upon request.

\section{Conflicts of Interest}

The authors declared that there were no conflicts of interest regarding the publication of this paper.

\section{Acknowledgments}

Financial supports from key project of NSFC-Shanxi coal based and low carbon joint fund (no. U1510204), NSFC (no. 51606039), and Natural Science Foundation of Jiangsu Province (no. BK20160684) are sincerely acknowledged.

\section{References}

[1] M. Li, W. Li, and S. Liu, "Hydrothermal synthesis, characterization, and $\mathrm{KOH}$ activation of carbon spheres from glucose," Carbohydrate Research, vol. 346, no. 8, pp. 999-1004, 2011.

[2] A. J. Romero-Anaya, M. Ouzzine, M. A. Lillo-Ródenas, and A. Linares-Solano, "Spherical carbons: synthesis, characterization and activation processes," Carbon, vol. 68, pp. 296-307, 2014.

[3] J. Fernández, A. Figueiras, M. Granda, J. Bermejo, and R. Menéndez, "Modification of Coal-Tar Pitch by Air-Blowing .1. Variation of Pitch Composition and Properties," Carbon, vol. 33, no. 3, pp. 295-307, 1995.

[4] Y. Guo, Y. Shao, W. Zhong, and K. Li, "Characteristics of oxidation stabilization process of coal pitch based spheres," Ciesc Journal, 2018.

[5] Y. Wang, X. Liu, Z. Li, and W. Qiao, "Oxidative stabilization of pitch spheres in fluidized bed and their carbonization behavior," Carbon Techniques, vol. 6, p. 3, 2010.

[6] H. Liu, H. Yin, M. Zhang, M. Xie, and X. Xi, "Numerical simulation of particle motion and heat transfer in a rotary kiln," Powder Technology, vol. 287, pp. 239-247, 2016.

[7] Q. Zheng and A. Yu, "Modelling the granular flow in a rotating drum by the Eulerian finite element method," Powder Technology, vol. 286, pp. 361-370, 2015. 
[8] R. Maione, S. Kiesgen De Richter, G. Mauviel, and G. Wild, "DEM investigation of granular flow and binary mixture segregation in a rotating tumbler: Influence of particle shape and internal baffles," Powder Technology, vol. 286, pp. 732-739, 2015.

[9] R. Yang, A. Yu, L. McElroy, and J. Bao, "Numerical simulation of particle dynamics in different flow regimes in a rotating drum," Powder Technology, vol. 188, no. 2, pp. 170-177, 2008.

[10] Y. Ding, R. Forster, J. Seville, and D. Parker, "Segregation of granular flow in the transverse plane of a rolling mode rotating drum," International Journal of Multiphase Flow, vol. 28, no. 4, pp. 635-663, 2002.

[11] P. Liu, R. Yang, and A. Yu, "DEM study of the transverse mixing of wet particles in rotating drums," Chemical Engineering Science, vol. 86, pp. 99-107, 2013.

[12] S. Jiang, Y. Ye, Y. Tan et al., "Discrete element simulation of particle motion in ball mills based on similarity," Powder Technology, vol. 335, pp. 91-102, 2018.

[13] S. Jiang, Y. Ye, M. He et al., "Mixing uniformity of irregular sand and gravel materials in a rotating drum with determination of contact model parameters," Powder Technology, 2019.

[14] B. Chaudhuri, F. J. Muzzio, and M. S. Tomassone, "Modeling of heat transfer in granular flow in rotating vessels," Chemical Engineering Science, vol. 61, no. 19, pp. 6348-6360, 2006.

[15] N. Gui, J. Yan, W. Xu et al., "DEM simulation and analysis of particle mixing and heat conduction in a rotating drum," Chemical Engineering Science, vol. 97, pp. 225-234, 2013.

[16] K. S. Mujumdar and V. V. Ranade, "CFD modeling of rotary cement kilns," Asia-Pacific Journal of Chemical Engineering, vol. 3, no. 2, pp. 106-118, 2008.

[17] F. Montagnaro, C. Tregambi, P. Salatino, O. Senneca, and R. Solimene, "Modelling oxy-pyrolysis of sewage sludge in a rotary kiln reactor," Fuel, vol. 231, pp. 468-478, 2018.

[18] M. U. Babler, A. Phounglamcheik, M. Amovic, R. Ljunggren, and K. Engvall, "Modeling and pilot plant runs of slow biomass pyrolysis in a rotary kiln," Applied Energy, vol. 207, pp. 123-133, 2017.

[19] D. Wenjing, B. Wang, and L. Cheng, "Experimental research and numerical analysis on thermal dynamic characteristics of rotary kiln," The Canadian Journal of Chemical Engineering, vol. 97, no. 4, pp. 1022-1032, 2019.

[20] J. Xie, W. Zhong, B. Jin, Y. Shao, and H. Liu, "Three-dimensional eulerian-eulerian modeling of gaseous pollutant emissions from circulating fluidized-bed combustors," Energy \& Fuels, vol. 28, no. 8, pp. 5523-5533, 2014.

[21] W. Zhong, A. Yu, G. Zhou, J. Xie, and H. Zhang, "CFD simulation of dense particulate reaction system: Approaches, recent advances and applications," Chemical Engineering Science, vol. 140, pp. 16-43, 2016.

[22] D. Gidaspow, Multiphase Flow and Fluidization: Continuum And Kinetic Theory Descriptions, Academic Press, 1994.

[23] A. Fluent, Release 15.0, Theory Guide, November, 2013.

[24] P. C. Johnson and R. Jackson, "Frictional-collisional constitutive relations for granular materials, with application to plane shearing," Journal of Fluid Mechanics, vol. 176, pp. 67-93, 1987.

[25] R. Ocone, S. Sundaresan, and R. Jackson, "Gas-Particle flow in a duct of arbitrary inclination with particle-particle interactions," AIChE Journal, vol. 39, no. 8, pp. 1261-1271, 1993.

[26] L. Le Guen, M. Piton, Q. Hénaut, F. Huchet, and P. Richard, "Heat convection and radiation in flighted rotary kilns: A minimal model," The Canadian Journal of Chemical Engineering, vol. 95, no. 1, pp. 100-110, 2017.
[27] T. Guan, G. Zhang, J. Zhao, J. Wang, and K. Li, "Insight into the oxidative reactivity of pitch fractions for predicting and optimizing the oxidation stabilization of pitch," Fuel, vol. 242, pp. 184-194, 2019.

[28] A. A. Boateng and P. V. Barr, "Granular flow behaviour in the transverse plane of a partially filled rotating cylinder," Journal of Fluid Mechanics, vol. 330, pp. 233-249, 1997.

[29] J. Mellmann, "The transverse motion of solids in rotating cylinders-forms of motion and transition behavior," Powder Technology, vol. 118, no. 3, pp. 251-270, 2001.

[30] Y. Demagh, H. Ben Moussa, M. Lachi, S. Noui, and L. Bordja, "Surface particle motions in rotating cylinders: Validation and similarity for an industrial scale kiln," Powder Technology, vol. 224, pp. 260-272, 2012. 


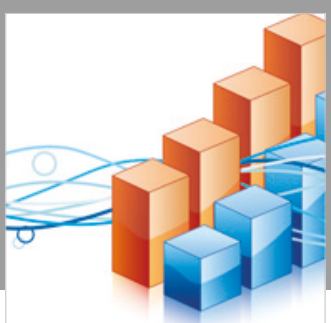

Advances in

Operations Research

\section{-n-m}
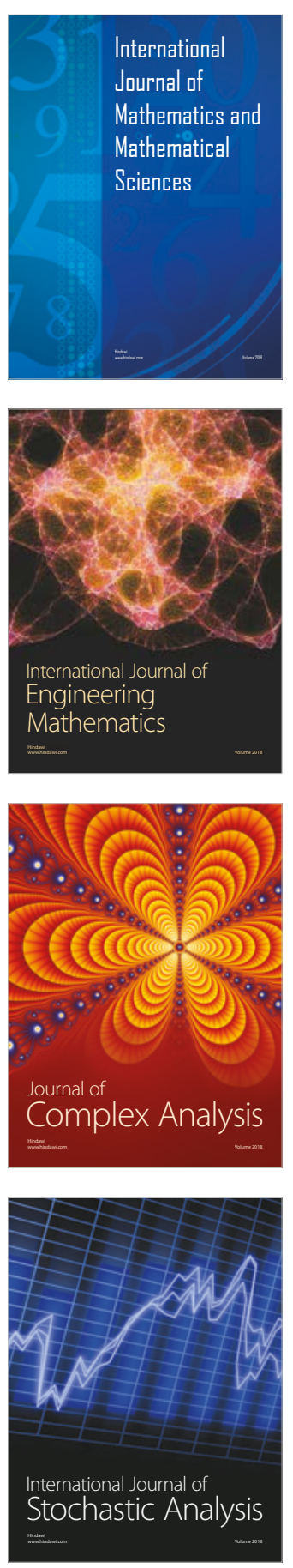
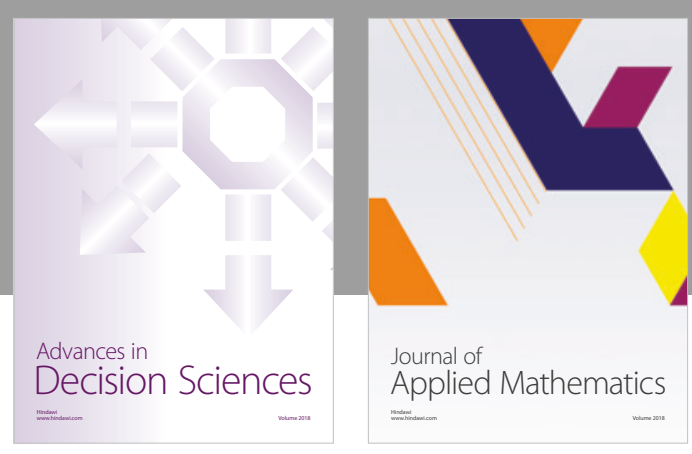

Journal of

Applied Mathematics
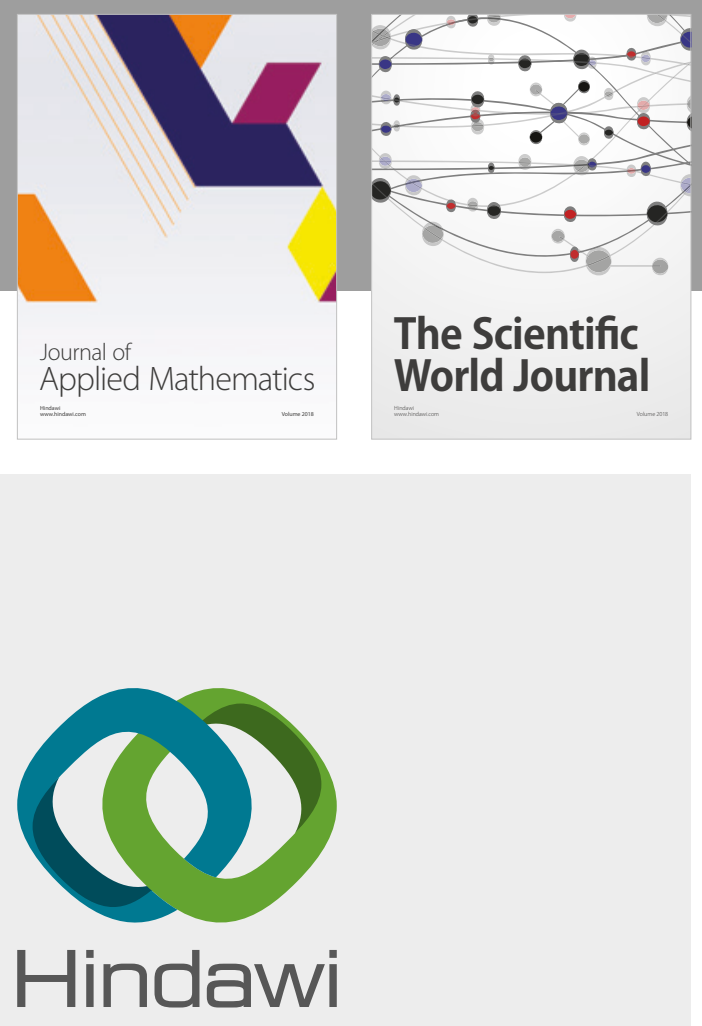

Submit your manuscripts at

www.hindawi.com

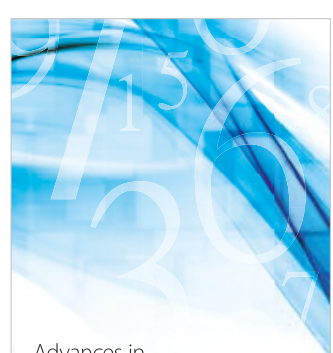

Advances in
Numerical Analysis
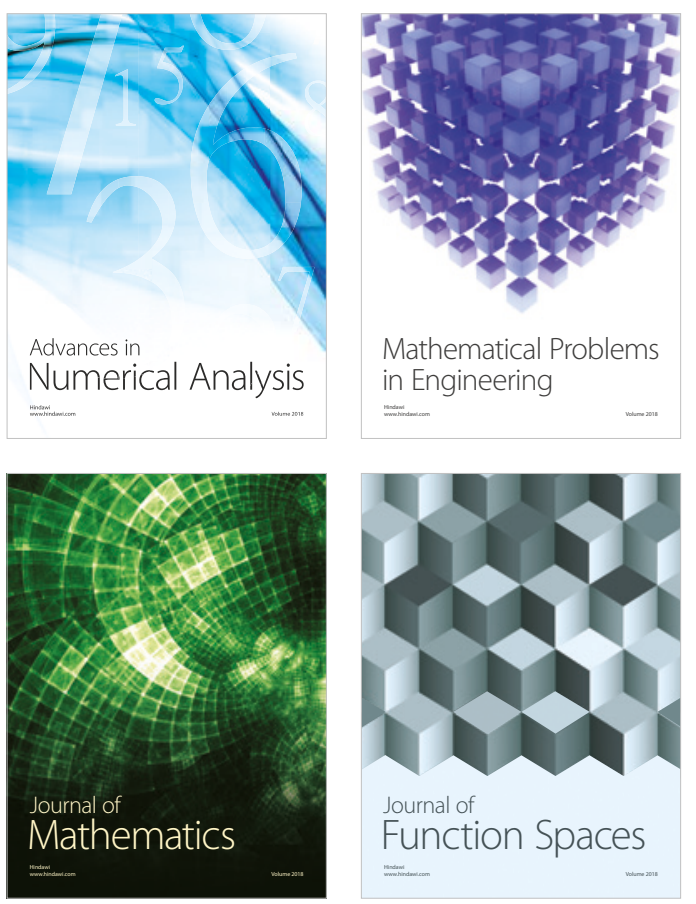

Mathematical Problems in Engineering

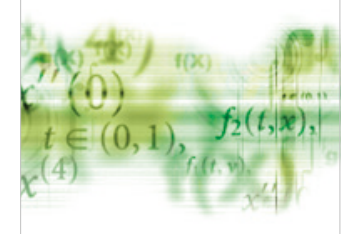

International Journal of

Differential Equations

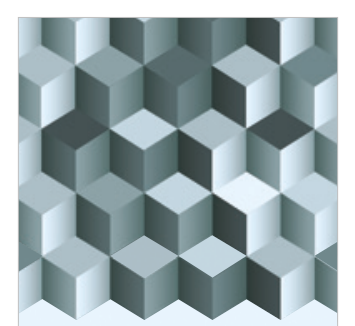

Journal of

Function Spaces
The Scientific

World Journal

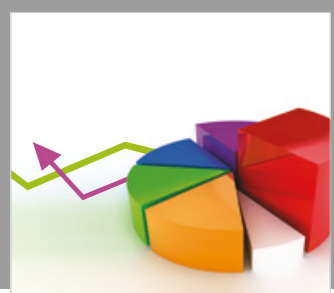

Journal of

Probability and Statistics
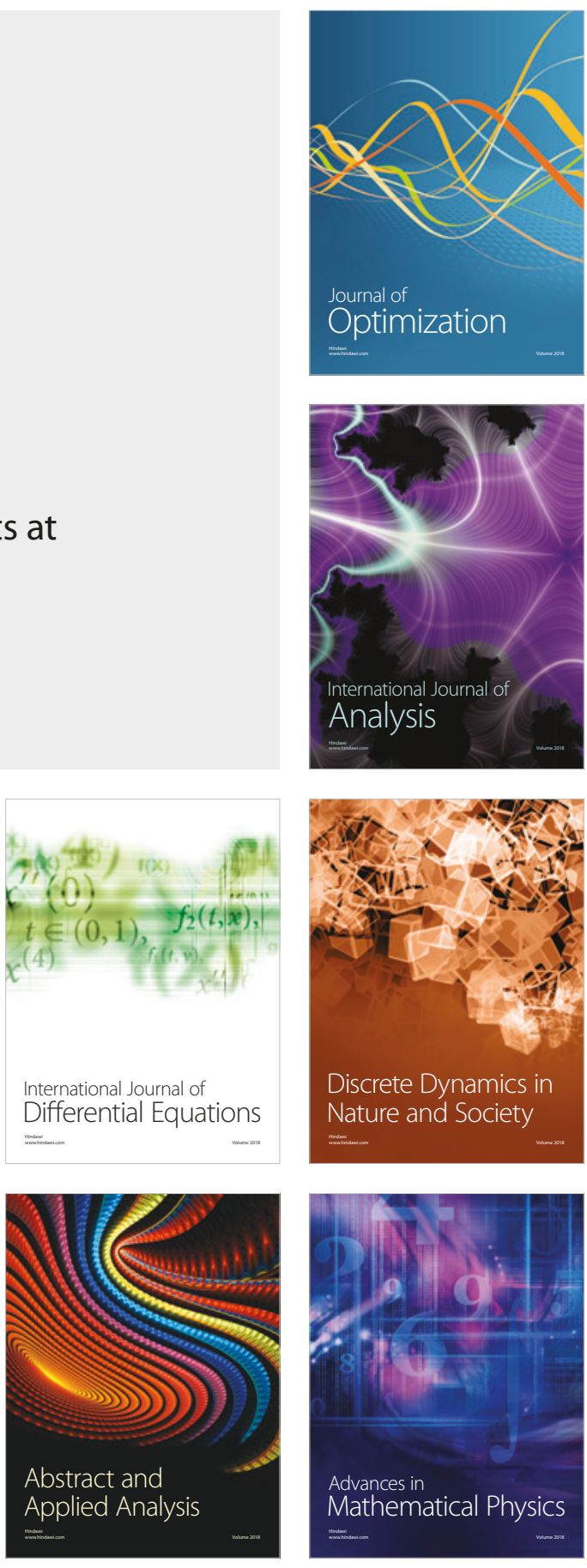